\title{
MicroRNA-276a Functions in Ellipsoid Body and Mushroom Body Neurons for Naive and Conditioned Olfactory Avoidance in Drosophila
}

\author{
Wanhe Li (李晚禾), ${ }^{1,2}$ Michael Cressy, ${ }^{1,3}$ Hongtao Qin (覃宏涛), ${ }^{1}$ Tudor Fulga, ${ }^{4}$ David Van Vactor, ${ }^{4}$ and Josh Dubnau ${ }^{1}$ \\ ${ }^{1}$ Cold Spring Harbor Laboratory, Cold Spring Harbor, New York 11724, ${ }^{2}$ Program of Molecular and Cellular Biology, Stony Brook University, Stony Brook, \\ New York 11790, ${ }^{3}$ Program of Genetics, Stony Brook University, Stony Brook, New York 11790, and ${ }^{4}$ Department of Cell Biology, Harvard Medical School, \\ Boston, Massachusetts 02115-3750
}

MicroRNA (miRNA)-mediated gene regulation plays a key role in brain development and function. But there are few cases in which the roles of individual miRNAs have been elucidated in behaving animals. We report a miR-276a::DopR regulatory module in Drosophila that functions in distinct circuits for naive odor responses and conditioned odor memory. Drosophila olfactory aversive memory involves convergence of the odors (conditioned stimulus) and the electric shock (unconditioned stimulus) in mushroom body (MB) neurons. Dopamine receptor DopR mediates the unconditioned stimulus inputs onto MB. Distinct dopaminergic neurons also innervate ellipsoid body (EB), where DopR function modulates arousal to external stimuli. We demonstrate that miR-276a is required in MB neurons for memory formation and in EB for naive responses to odors. Both roles of miR-276a are mediated by tuning DopR expression. The dual role of this miR-276a::DopR genetic module in these two neural circuits highlights the importance of miRNA-mediated gene regulation within distinct circuits underlying both naive behavioral responses and memory.

\section{Introduction}

MicroRNAs (miRNAs) are small RNAs ( $\sim 21-23 \mathrm{nt}$ long) thought to regulate as many as $50 \%$ of genes at the posttranscriptional level by binding to complementary sequences in target mRNAs (Bartel, 2009). MiRNA-mediated regulation has emerged as a key mechanism governing synaptic plasticity (Schratt et al., 2007). We demonstrate a role for miR-276a in Drosophila for both naive responses to odors and for olfactory memories. We focused on this particular miRNA gene because it maps nearby to one of the mutations identified from a forward mutagenesis screen for memory defects (Dubnau et al., 2003). By manipulating spatial and temporal function of this miRNA, we uncovered a complex role in both naive and conditioned odor

Received Aug. 20, 2012; revised Feb. 8, 2013; accepted Feb. 19, 2013.

Author contributions: W.L. and J.D. designed research; W.L., M.C., and H.Q. performed research; T.F. and D.V.V. contributed unpublished reagents/analytic tools; W.L. and J.D. analyzed data; W.L. and J.D. wrote the paper.

This work was supported by National Institutes of Health (NIH) Grant TR01 (5R01NS067690-03), NIH Grant 5R01MH06944, DART NeuroScience LLC, and the Beckman Foundation. We thank Kyung-An Han, Tim Lebestky, Glenn Turner, Koen Venken, Leslie Vosshall, Yi Zhong, BACPAC Resources, and BestGene for protocols, strains, and reagents. We also thank Allison Blum, Stephane Castel, Christine Cho, Jonathan Coravo, Julius Brennecke, Benjamin Czech, Nabanita Chatterjee, Gregory Hannon, Huaien Wang, Josh Huang, Sitharthan Kamalakaran, Maurice Kernan, Lisa Krug, Fei Li, Lisa Prazak, Yichun Shuai, Tim Tully, Glenn Turner, Shouzhen Xia, Lei Wang, Chaolin Zhang, and Yi Zhong for critical discussions, technical support, and comments on the manuscript.

The authors declare no competing financial interests.

Correspondence should be addressed to Josh Dubnau at the above address. E-mail: dubnau@cshl.edu.

H. Qin's present address: Department of Biomedical Engineering, College of Biology, Hunan University, 1 DengGao Road, Yuelu District, Changsha 410082, China.

T. Fulga's present address: Institute of Molecular Medicine, University of Oxford, John Radcliffe Hospital, Headington, 0xford OX3 9DS, UK.

DOI:10.1523/JNEUROSCI.4004-12.2013

Copyright $\odot 2013$ the authors $\quad 0270-6474 / 13 / 335821-13 \$ 15.00 / 0$ responses. We also demonstrate that DopR, a type-one dopamine receptor, is a functional downstream effector of miR-276a.

Pavlovian olfactory conditioning in Drosophila has provided a powerful system to investigate genetic and circuit mechanisms of memory (Margulies et al., 2005; Keene and Waddell, 2007; Busto et al., 2010). A model has emerged in which mushroom body (MB) neurons integrate odor conditioned stimulus (CS) inputs with neuromodulatory unconditioned stimulus inputs. For aversive learning, the unconditioned stimulus information is mediated by several characterized dopaminergic neurons (Schwaerzel et al., 2003; Claridge-Chang et al., 2009; Krashes et al., 2009; Aso et al., 2010) projecting onto $\mathrm{MB}$ neurons. Formation of all stages of aversive olfactory memory (short, middle, and long-term) requires DopR expression in MB (Kim et al., 2007a; Qin et al., 2012). However, long-term memory (LTM) involves a broader neural circuit because CREB-mediated gene expression is required outside $\mathrm{MB}$, in dorsalanterior-lateral neurons that send inputs to MB (Chen et al., 2012), and NMDA-receptor function is required for LTM in R4 subtypes of ellipsoid body (EB) neurons (Wu et al., 2007).

Outside MB, DopR function also is required in modulating various forms of arousal to external stimuli, including ethanol, cocaine, and caffeine (Andretic et al., 2008; Kong et al., 2010; Van Swinderen and Andretic, 2011), as well as startle-induced arousal caused by repetitive air puffs (Lebestky et al., 2009). For certain forms of arousal, DopR expression is required within R2/R4m subsets of EB neurons (Lebestky et al., 2009; Kong et al., 2010), which include the cell type(s) where NMDA-receptor function is needed for olfactory LTM (Wu et al., 2007). Thus naive responses to external stimuli and long-lived conditioned responses to odors share a role for EB neurons and also share a role for dopamine signaling onto DopR. 
In this study, we show that miR-276a is required within $\mathrm{MB}$ for conditioned olfactory LTM and in R2/R4m subtypes of EB neurons for naive olfactory avoidance. Furthermore, we are able to fully suppress both the LTM and naive olfactory response defects of miR-276a disruptions simply by reducing the DopR copy number. Overexpression of DopR within MB also is sufficient to phenocopy LTM defects of the miR-276a mutants. We propose a model in which miR-276a fine-tunes the levels of DopR within MB for conditioned olfactory LTM and within EB for naive odor responses.

\section{Materials and Methods}

Fly stocks. Fly stocks were cultured in standard fly food and room temperature $\left(22.5^{\circ} \mathrm{C}\right)$. The wild-type flies used in this study were $w^{1118}$ (iso1CJ). All other mutant strains and transgenic strains were backcrossed to this wild-type strain for at least five generations. The $m i R$ $276^{\text {Rosa }}$ mutant was originally generated in the Tully laboratory from a forward mutagenesis screen by inserting a P-element $\mathrm{p}\{\mathrm{lacW}\}$ (Dubnau et al., 2003). The null allele $m i R-276 a^{D 8}$ was generated by providing transposase $\Delta 2-3$ in trans and mobilizing the P-element imprecisely. To detect the molecular lesion in $m i R-276 a^{D 8}$, genomic DNA from the $m i R$ $276 a^{D 8 / R o s a}$ animals was purified and PCR-amplified by primers priming flanking regions (forward primer: 5'-AATAGAGTTGACAAAGCG TTCGGCGCCCACG-3'; reverse primer: 5' -GCGGAGGAAGGGAATC TGGCACTCGAATCG-3') with the Roche Expand Long Range dNTP pack (Cat. No. 04829034001, Roche). The PCR product was sequenced and it was determined that in the $m i R-276 a^{D 8}$ allele, a $\sim 3.6 \mathrm{~kb}$ genomic region to the right of the P-element insertion site was deleted and a $\sim 2.8$ $\mathrm{kb}$ residual sequence of the P-element was left in the genome. Animals homozygous for $m i R-276 a^{D 8}$ are semilethal and few animals survive during late pupal stage. Similarly, the precise excision alleles $m i R-276 a^{A 6}$ and $m i R-276 a^{D 2.2}$ were also generated by providing transposase $\Delta 2-3$ in trans and mobilizing the P-element precisely. PCRs (forward primer: $5^{\prime}$-AA TAGAGTTGACAAAGCGTTCGGCGCCCACG-3'; reverse primer: 5' TGAACGTAGGAACTCTATACCTCGCTGATGG-3') were used to verify that the P-elements were removed and genomic structures were restored in these alleles.

The bacterial artificial chromosome (BAC) rescue genomic constructs were obtained from BACPAC Resources Center. These BAC clones flank the miR-276a precursor regions, but were selected carefully to avoid any sequence flanking upstream or downstream genes. The names and approximate sizes of the constructs are as follows: $\mathrm{CH} 322-133 \mathrm{G} 18(\sim 20$ $\mathrm{kb}), \mathrm{CH} 322-151 \mathrm{H} 13(\sim 19 \mathrm{~kb})$, and CH321-46B15 ( 75 kb). These BAC clones were engineered into the attB-P $[\mathrm{acman}]-\mathrm{Cm}^{\mathrm{R}}-\mathrm{BW}$ vector (Venken et al., 2009) and these transgene constructs were directly injected and permanently integrated at specific docking sites (engineered genomic loci containing attP sequence) in the genome using $\Phi \mathrm{C} 31$ transposase (Venken et al., 2006, 2009). We selected the 9736 (53B2) docking site ( $\mathrm{P}[\mathrm{acman}]$ Resources, www.pacmanfly.org). This docking site is farther away from annotated genes and presumably will not affect animal behavior. The transgenic fly injection services were provided by BestGene. Because the docking site stock itself contains a yellow ${ }^{1}$ mutant allele on the $\mathrm{X}$ chromosomes and this mutation could potentially impair animal behavior, we crossed male transformants with wild-type flies and select male progenies before starting subsequent backcrossing to remove $y e l l o w^{1}$.

The UAS::miR-276a-4.7Kb rescue construct was made by cloning a $\sim 4.7 \mathrm{~kb}$ genomic region from wild-type flies into the pUAST vector. Forward primer $5^{\prime}$-GTTTGTGCCTCAAGTGGCAGTCATAAATTTGA G-3' and reverse primer 5'-AACCGCACCTCAATCGCCCTTTACTT GG-3' were used to PCR-amplify a $\sim 4.7 \mathrm{~kb}$ genomic region containing the miR-276a precursor and largely upstream regions. The PCR product was cloned with a Zero Blunt TOPO PCR Cloning Kit (Invitrogen) and then subcloned into the pUAST vector. The resulting pUAST-miR-276a$4.7 \mathrm{~Kb}$ constructs were injected at BestGene by standard P-transposasemediated integration.

The UAS::EGFP::miR-276aSPONGE and UAS::EGFP::SCRAMBLED transgenic flies were generated as previously described (Loya et al., 2009). The "sponge" sequence used for UAS::EGFP::miR-276aSPONGE is as fol-
lows:5'-TCTAGAAGAGCACGGTACTAGTTCCTACCGTAGAGCACGG TACTAGTTCCTACCGTAGAGCACGGTACTAGTTCCTACCGTAGAG CACGGTACTAGTTCCTACCGTAGAGCACGGTACTAGTTCCTACCG TAGAGCACGGTACTAGTTCCTACCGTAGAGCACGGTACTAGTTCC TACCGTAGAGCACGGTACTAGTTCCTACCGTAGAGCACGGTACTA GTTCCTACCGTAGAGCACGGTACTAGTTCCTACTCGAG-3'. And the "sponge" sequence used for UAS::EGFP::SCRAMBLED is as follows: 5'-CT CGAGTTAGAATTTAAACCTCACCATGATGCATTAGAATTTAAACCT CACCATGAGCGGTTAGAATTTAAACCTCACCATGAAGGCTTAGAA TTTAAACCTCACCATGAGTCCTTAGAATTTAAACCTCACCATGAT GGCTTAGAATTTAAACCTCACCATGAACTTTTAGAATTTAAACCTC ACCATGAGGCATTAGAATTTAAACCTCACCATGATAGATTAGAATT TAAACCTCACCATGAGCCTTTAGAATTTAAACCTCACCATGATCTA GA-3'. Two transformant lines (presumably different insertion sites) of each transgene were randomly selected for the behavior study. For clarity, these transformant lines were named as follows: UAS::EGFP:: SPONGE\#1, UAS::EGFP::SPONGE\#2, UAS::EGFP::SCRAMBLED\#1, and UAS::EGFP::SCRAMBLED\#4.

The GAL4 stocks used in this study included the following: panneuronal driver elav, olfactory sensory neuron driver Or83b, antenna lobe projection neuron driver GH146, antenna lobe local neuron driver GH298, MB drivers OK107 and c747, EB drivers $c 232$ and $c 547$, and heat-shock GAL4 (hs-GAL4). Two GAL4 stocks combined with tubulin promoter-driven temperature-sensitive GAL80 transgenes elav; GAL80 ${ }^{\text {ts }}$ and $G A L 80^{t s} ;$;OK107 were also used. UAS::mCD8::GFP (Bloomington Stock Center) was also used to virtualize GAL4 expression patterns.

Two strong alleles of DopR gene, $d u m b^{1}$ and $d u m b^{2}$ (Kim et al., 2007a), were used in this study.

Quantitative real-time PCR. TaqMan MicroRNA Assays (Applied Biosystems) were used to quantitate the expression level of miR-276a in wild-type, mutant, and rescue animals. TaqMan miRNA assays for $m i R$ $276 a$ (assay ID 000297) and the endogenous control $2 s r R N A$ (assay ID 001766), MultiScribe reverse transcription kit (4366596), and TaqMan Universal PCR Master Mix No AmpErase UNG (4324018) were purchased from Applied Biosystems. The QPCR was performed according to the assay manual. In brief, massive numbers of fly heads were collected for each genotype and total RNA was purified with Trizol (Invitrogen) and treated by DNaseI (Promega). Following reverse transcription (RT) reaction with miRNA-specific stem-loop RT primers, QPCRs were performed with TaqMan MicroRNA probes in an Applied Biosystems 7900 HT Fast Real-Time PCR System. Threshold cycle (Ct) values obtained from the QPCRs were further converted to relative fold changes with a $\Delta \Delta$ Ct method (Schmittgen, 2001).

TaqMan Gene Expression Assays (Applied Biosystems) were used to quantitate the expression levels of $Z f h 2, D o p R$, Pino, Nf1, and $d p r$ genes for validating potential miR-276a targets. TaqMan Gene Expression Assays for Zfh2 (assay ID Dm01825551_m1), DopR (assay ID Dm02134813_m1), Pino (assay ID Dm01845906_m1), Nf1 (assay ID Dm02151064_g1), dpr (assay ID Dm01836227_m1); the endogenous control RpII140 (assay ID Dm02134593_g1); High Capacity RNA-tocDNA kit (4387406); and TaqMan Gene Expression Master Mix (4369016) were purchased from Applied Biosystems. The QPCR was performed according to the assay manual. In brief, massive numbers of fly heads were collected for each genotype and total RNA was purified with Trizol (Invitrogen) and treated by DNaseI (Promega). Following RT reaction, QPCRs were performed with TaqMan Gene Expression Assay probes in an Applied Biosystems 7900HT Fast Real-Time PCR System. $\mathrm{Ct}$ values obtained from the QPCRs were further converted to relative fold changes with a $\Delta \Delta \mathrm{Ct}$ method (Schmittgen, 2001).

Behavior assays. Olfactory associative memory was tested by training 2-3-d-old flies in a T-maze apparatus using a Pavlovian conditioning paradigm (Tully and Quinn, 1985; Tully et al., 1994). Approximately 100 flies were loaded into an electrifiable training grid. For a single training session, flies were exposed sequentially to one odor [the conditioned stimulus, $(\mathrm{CS}+)]$, which was paired with a $60 \mathrm{~V}$ electric shock and then a second odor [the unconditioned stimulus (CS-)] without shock. Three minutes after this training session, the flies were tested and allowed to choose between the two odors. A half performance index was calculated by subtracting the number of flies that chose incorrectly from the num- 
ber of flies that chose correctly, and then dividing that number by the total number of flies in the experiment. The same protocol was then performed with another group of 100 flies and reciprocal odor presentation. The final performance index was calculated by averaging both reciprocal half performance indices. The LTM experiment was an adaptation of this training protocol. Flies were subjected to 10 such training sessions in robotic trainers spaced out with a 15 min rest interval between each. Flies then were transferred into food vials and incubated at $18^{\circ} \mathrm{C}$ until being tested $24 \mathrm{~h}$ after the training. A massed training protocol was also performed (10 consecutive single training sessions in robotic trainers without rest intervals). All genotypes were trained and tested in parallel, and rotated between all the robotic trainers to ensure a balanced experiment. Odor pairs and concentrations used for these behavior paradigms are as follows: 3-octanol (OCT, $\left.1.5 \times 10^{-3} \mathrm{v} / \mathrm{v}\right)$ and 4-methylcyclohexanol $\left(\mathrm{MCH} ; 1 \times 10^{-3} \mathrm{v} / \mathrm{v}\right)$, or OCT $\left(1.5 \times 10^{-3} \mathrm{v} / \mathrm{v}\right)$ and benzaldehyde $\left(\mathrm{BA} ; 0.5 \times 10^{-3} \mathrm{v} / \mathrm{v}\right)$. Pure odors were purchased from Sigma-Aldrich and delivered as the stated concentrations with air flow at $750 \mathrm{ml} / \mathrm{min}$.

Olfactory avoidance was quantified by exposing naive flies to each odor versus air in the T-maze (i.e., odor from the left and air from the right). After $2 \mathrm{~min}$, flies in each arm of the T-maze were counted. Subsequently the directions of odor and air were switched (i.e., odor from the right and air from the left) and another group of naive flies was tested. A half performance index was calculated by subtracting the number of flies that chose the odor from the number of flies that chose air, and then dividing that number by the total number of flies in the experiment. The final performance index was calculated by averaging both reciprocal half performance indices. The odor concentrations used for olfactory acuity tests were indicated in each figure. Pure odors were purchased from Sigma-Aldrich and delivered as the stated concentrations with air flow at $750 \mathrm{ml} / \mathrm{min}$.

Shock reactivity was quantified by exposing naive flies to two electrifiable grids in the T-maze, while delivering a $60 \mathrm{~V}$ electric shock to one of the grids. Flies were allowed 2 min to choose. A performance index was calculated by subtracting the number of flies that chose the shock from the number of flies that chose to avoid the shock, and dividing that number by the total number of flies in the experiment.

In all cases, behavior experiments within a figure were performed in parallel.

Quantification of 24 h embryo-hatching rate. Crosses with corresponding genotypes were made and maintained in cages on agar plates containing fruit juice for a few days ( $3-5 \mathrm{~d}$ ). Early in the morning, the agar plates were replaced with fresh new ones and yeast paste to make sure female flies start to lay fertilized eggs in large quantities. Then a $4 \mathrm{~h}$ egg collection was performed. Twenty-four hours after the end of egg collection, hatched embryos from each cross were counted and hatching rates were calculated by dividing the number of hatched embryos by the total number of embryos.

$G A L 80^{\text {ts }}$ temperature-shift experiment. The female virgin flies with genotypes of elav; $G A L 80^{t s}$ or $G A L 80^{t s} ;$;OK107 were collected and crossed to WT, UAS::EGFP::miR-276aSPONGE, and UAS::EGFP::SCRAMBLED transgenic flies. All the crosses were raised at the permissive temperature $\left(29^{\circ} \mathrm{C}\right)$. Upon eclosion, we separated the progenies of each cross into two groups: one was continuously incubated at the permissive temperature $\left(29^{\circ} \mathrm{C}\right)$ and the other one was incubated at the restrictive temperature $\left(18^{\circ} \mathrm{C}\right)$. Both groups were incubated for an additional $72 \mathrm{~h}$ before testing for the avoidance behavior and olfactory memory. The avoidance behavior test was described as above except for the use of $\mathrm{MCH}$ that was three times more concentrated $\left(3 \times 10^{-3} \mathrm{v} / \mathrm{v}\right)$. Permissive temperature incubation during the entire process of development affected the animal behavior. We raised the testing odor concentration to ensure that a similar level of avoidance index in WT flies with animals raised at $22.5^{\circ} \mathrm{C}$ can be obtained with animals raised at $29^{\circ} \mathrm{C}$. Following temperature-shift treatment, olfactory avoidance tests were conducted at $25^{\circ} \mathrm{C}$ in an environment-controlled room with $70 \%$ humidity. LTM experiments were conducted by performing $10 \times$ spaced training sessions at $25^{\circ} \mathrm{C}$ in an environment-controlled room with $70 \%$ humidity. The trained flies were kept at $18^{\circ} \mathrm{C}$ before testing for LTM at $25^{\circ} \mathrm{C} 24 \mathrm{~h}$ later.

Imaging. Expression levels of GAL4 lines were virtualized by UAS::mCD8::GFP with confocal microscopy as described previously (Blum et al., 2009). DopR antibody staining was performed with a method and an anti-DopR antibody described previously (Lebestky et al., 2009).

Statistics. Statistical analyses were performed using JMP software. Student's $t$ test (2-tailed) was used for comparisons between two groups. One-way ANOVA followed by post hoc analysis was used for comparisons of multiple groups. Behavioral data from the Pavlovian memory task are normally distributed and are shown in all figures as means \pm SEM (Tully et al., 1994). QPCR data are presented as means \pm SEM of fold changes.

\section{Results}

\section{Genetic reagents to manipulate the $m i R-276 a$ gene locus}

The $m i R-276 a^{\text {Rosa }}$ mutant isolated from a forward mutagenesis screen (Dubnau et al., 2003) has a p $\{$ lacW $\}$ element inserted 1.2 $\mathrm{kb}$ upstream of the gene region coding for the predicted dme-mir$276 a$ precursor. dme-mir-276a and the $\mathrm{p}\{\mathrm{lacW}\}$ element insertion site fall within a large intergenetic region of $\sim 100 \mathrm{~kb}$, where there are no known or predicted protein coding genes within $\sim 50$ $\mathrm{kb}$ either upstream or downstream of the miRNA sequence (Fig. 1A). dme-mir-276b, which also belongs to the dme-mir-276 gene family, sits $\sim 45 \mathrm{~kb}$ upstream. Both of these miRNA loci produce RNA precursors that can contribute to the expression of a miRNA passenger sequence, miR-276*, with identical sequence from the two loci (Fig. $1 B, C$ ). The mature miRNAs, miR-276a and miR-276b, differ from each other by only $1 \mathrm{nt}$. Expression profiling of miRNAs from cultured Drosophila S2 cells or various tissues indicates that the abundance of miR-276a is 10 -fold higher than miR-276b and most miR-276* arises from the $d m e-$ mir-276a precursor locus (Czech et al., 2008).

To investigate the function of $m i R-276 a$ locus in behavior, we first generated a suite of reagents to manipulate miR-276a expression with both temporal and cell-type specificity. We generated both precise and imprecise excisions of the $\mathrm{p}\{\mathrm{lacW}\}$ element insertion (Fig. 1A; see Materials and Methods). In the $m i R-276 a^{D 8}$ allele, $\mathrm{a} \sim 3.6 \mathrm{~kb}$ genomic region to the right of the $\mathrm{p}\{\mathrm{lacW}\}$ element insertion site was deleted and $\mathrm{a} \sim 2.8 \mathrm{~kb}$ residual sequence of the P-element was left in the genome. $m i R-276 a^{D 8}$ therefore removes the entire mir-276a precursor and can be considered a null allele. In the $m i R-276 a^{A 6}$ and the $m i R-276 a^{D 2.2}$ alleles, the P-element is almost completely removed and no flanking deletions were detected. These excision alleles therefore are predicted to restore the normal function of this locus (Fig. 1A). In addition to these mutant alleles, we generated transgenic rescue animals containing genomic BAC clones, CH322-133G18 ( 20 $\mathrm{kb}), \mathrm{CH} 322-151 \mathrm{H} 13(\sim 19 \mathrm{~kb})$ and $\mathrm{CH} 321-46 \mathrm{~B} 15(\sim 75 \mathrm{~kb})$, which were carried in $\mathrm{p}$ [acman] vectors (Venken et al., 2006, 2009). These BAC clones cover the mir-276a precursor region and do not include any nearby protein coding genes or the mir$276 b$ precursor region (Fig. $1 A$ ).

To characterize the expression of miR-276a in the above mutants and BAC rescue transgenes, we used QPCR to detect miR$276 a$ levels in fly heads (Figs. $1 D, 2 C$ ). In the $m i R-276 a^{\text {Rosa }}$ homozygous mutant animal heads, miR-276a expression level was reduced by $\sim 40 \%$ compared with wild-type animals. In the miR-276a $a^{D 8}$ homozygous mutant animal heads, miR-276a expression (Fig. $1 D ; F_{(3,18)}=25.09, p<0.05$ ) was nearly eliminated (the low residual expression presumably derives from $m i R-276 b$ locus, which differs from miR-276a by only $1 \mathrm{nt}$ ). This is consistent with the conclusion that $m i R-276 a^{D 8}$ is a null allele of $m i R$ $276 a$, while $m i R-276 a^{R o s a}$ is a hypomorphic allele. Animals transheterozygous for the two mutant alleles $m i R-276 a^{D 8}$ and $m i R-276 a^{R o s a}\left(m i R-276 a^{D 8 / R o s a}\right)$ yield defective miR-276a expression that is intermediate between that of $m i R-276 a^{\text {Rosa }}$ and $m i R$ $276 a^{D 8}$ homozygous animals (Fig. $1 D ; F_{(3,18)}=25.09, p<0.05$ ). 
Because the homozygous $m i R-276 a^{D 8}$ mutant is semilethal (few survive to adulthood), we used $m i R-276 a^{D 8 / R o s a}$ as a viable but strong allele combination for behavioral experiments. For the $\mathrm{BAC}$ rescue transgenes, only $\mathrm{CH} 321-46 \mathrm{~B} 15$, the largest of the three constructs $(\sim 75 \mathrm{~kb}$ genomic fragment) restored miR-276a expression (Fig. $2 C ; F_{(3,19)}=16.06$, $p<0.05)$.

\section{miR-276 $a^{D 8 / R o s a}$ mutant animals exhibit} defective long-term olfactory memory and naive olfactory avoidance

An LTM defect originally was reported for the $m i R-276 a^{\text {Rosa }}$ hypomorphic allele (Dubnau et al., 2003). We tested shortterm and long-term olfactory memory as well as task-relevant sensorimotor responses to the odors and electric shock using the strong $m i R-276 a^{D 8 / R o s a}$ allele combination. We found that the miR$276 a^{D 8 / R o s a}$ animals exhibited significantly defective performance for LTM measured $24 \mathrm{~h}$ after 10 spaced training sessions, while animals heterozygous for $m i R$ $276 a^{D 8}$ or $m i R-276 a^{\text {Rosa }}$ allele performed normally compared with WT (Fig. 1E; $\left.F_{(3,60)}=11.77, p<0.05\right)$. However, the miR-276a $a^{\text {D8/Rosa }}$ animals also exhibited significantly defective naive avoidance responses (Fig. $1 F, I$ ) to $\mathrm{MCH}$ (Fig. $1 F, I$; $\left.F_{(3,18)}=5.88, p<0.05\right)$ and OCT (Fig. 1I; $F_{(3,34)}=9.51, p<0.05$ ), but not BA (Fig. $1 I ; F_{(3,20)}=1.88$, not significant) at the concentrations used for our standard memory assay $\left(1 \times 10^{-3} \mathrm{v} / \mathrm{v}, 1.5 \times 10^{-3}\right.$ $\mathrm{v} / \mathrm{v}$, and $0.5 \times 10^{-3} \mathrm{v} / \mathrm{v}$ respectively for $\mathrm{MCH}, \mathrm{OCT}$, and BA), compared with WT or heterozygous mutant controls. At 10fold higher concentrations, responses appeared normal for OCT (Fig. $1 I ; F_{(3,20)}=$ 4.06, not significant), but not for $\mathrm{MCH}$ (Fig. $1 I ; F_{(3,20)}=19.74, p<0.05$ ). These observations raised the possibility that the reduced naive odor response of strong allele combinations of $m i R-276 a$ contributes to the olfactory memory defect (but see below). Avoidance of electric shock $(60 \mathrm{~V})$ appeared normal in all genotypes (Fig. $1 G ; F_{(3,11)}=0.20$, not significant).

\section{miR-276a function underlies naive} olfactory avoidance defects

In addition to the complementation tests shown in Figure $1 E, I$, we also tested whether the naive odor avoidance defect was reverted with the precise excision alleles in which the P-element was removed and the genomic structure was restored. Indeed, animals transheterozygous for $m i R$ $276 a$ mutant alleles (hypomorphic allele $m i R-276 a^{\text {Rosa }}$ or null allele $m i R-276 a^{D 8}$ ) and either of the two precise excision alleles $\left(m i R-276 a^{A 6}\right.$ or $\left.m i R-276 a^{D 2.2}\right)$ exhibit normal naive olfactory
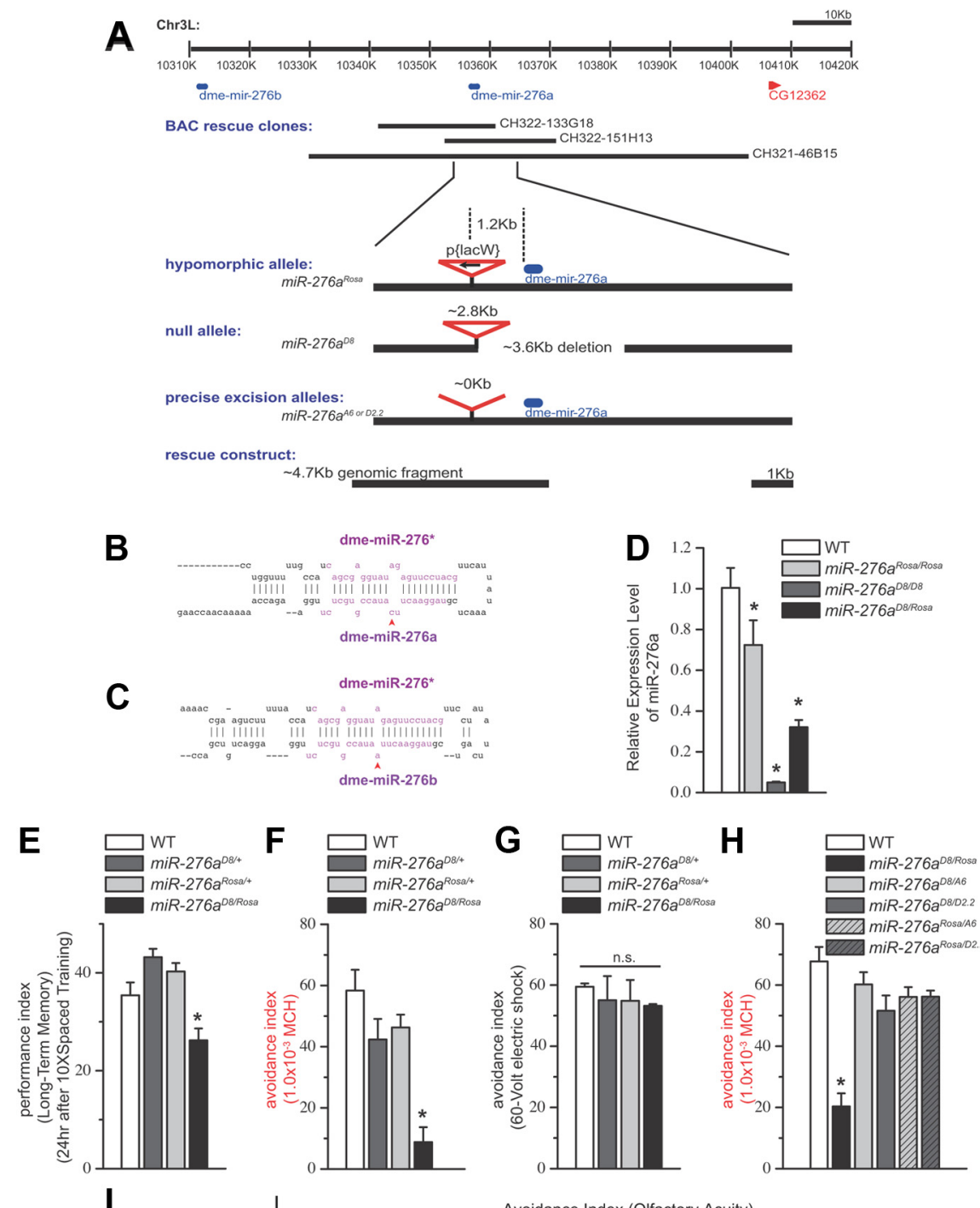

\begin{tabular}{l|c|c|c|c|c}
\multicolumn{1}{c|}{ genotype } & \multicolumn{5}{c}{ Avoidance Index (Olfactory Acuity) } \\
\hline & $\begin{array}{c}\mathrm{MCH} \\
1.0 \times 10^{-2} \mathrm{v} / \mathrm{v}\end{array}$ & $\begin{array}{c}\mathrm{MCH} \\
1.0 \times 10^{-3} \mathrm{v} / \mathrm{v}\end{array}$ & $\begin{array}{c}\text { OCT } \\
1.5 \times 10^{-2} \mathrm{v} / \mathrm{v}\end{array}$ & $\begin{array}{c}\text { OCT } \\
1.5 \times 10^{-3} \mathrm{v} / \mathrm{v}\end{array}$ & $\begin{array}{c}\text { BA } \\
0.5 \times 10^{-3} \mathrm{v} / \mathrm{v}\end{array}$ \\
\hline $\mathrm{WT}$ & $74.66 \pm 5.07$ & $58.33 \pm 6.79$ & $71.96 \pm 2.93$ & $54.92 \pm 3.43$ & $49.91 \pm 6.15$ \\
\hline miR-276a & $74.10 \pm 3.68$ & $42.30 \pm 6.74$ & $64.67 \pm 0.78$ & $36.64 \pm 2.40$ & $50.49 \pm 4.19$ \\
\hline miR-276a & $74.01 \pm 3.79$ & $35.05 \pm 11.73$ & $63.06 \pm 2.84$ & $50.37 \pm 2.50$ & $43.83 \pm 4.59$ \\
\hline miR-276a & $33.72 \pm 5.45$ & $8.81 \pm 4.83$ & $61.95 \pm 1.66$ & $36.02 \pm 3.77$ & $36.80 \pm 3.26$
\end{tabular}

Figure 1. Genetic and behavioral characterization of miR-276a gene locus. $\boldsymbol{A}-\boldsymbol{C}$, The dme-miR-276a gene falls into a large intergenic region $(\boldsymbol{A})$. The $\mathrm{p}\{$ lacW $\}$ element that causes the miR-276a ${ }^{R o s a}$ mutant phenotype is inserted $1.2 \mathrm{~kb}$ upstream of the dme-mir-276a precursor region. The structure of each mutant allele or transgene is illustrated, including hypomorphic allele miR-276 $a^{\text {Rosa }}$, null allele miR-276a $a^{D 8}$, and precise excision alleles miR-276a $a^{A 6}$ and $m i R-276 a^{D 2.2}$. The structure and relative sizes of rescue constructs, including three $B A C$ rescue clones and a $4.7 \mathrm{~kb}$ genomic fragment, also are shown $(\boldsymbol{A})$. The $d m e-m i R-276$ gene family produces two miRNA precursors, which give rise to three miRNAs (miRBase: http://www.mirbase.org): dme-miR-276a, dme-miR-276b, and dme-miR-276* (B, C). D, The relative expression level of miR-276a in the heads of WT, miR-276a ${ }^{\text {Rosa/Rosa }}$ miR-276a ${ }^{D / D 8}$, and miR-276a $a^{D 8 / R o s a}$ animals, measured by QPCR. ${ }^{*} p<0.05 ; N=\sim 3-8 . \boldsymbol{E}$, miR-276a $a^{D 8}$ and miR-276a ${ }^{R o s a}$ alleles failed to complement each other for LTM measured $24 \mathrm{~h}$ after 10 spaced training sessions. ${ }^{*} p<0.05 ; N=16 . \boldsymbol{F}, m i R-276 a^{D 8}$ and miR-276a ${ }^{\text {Rosa }}$ alleles failed to complement each other for olfactory avoidance test with $\mathrm{MCH}\left(1.0 \times 10^{-3} \mathrm{v} / \mathrm{v}\right) .{ }^{*} p<0.05 ; N=$ $\sim 4-6.6$, Shock avoidance (60 V) appeared normal in WT, miR-276 $a^{\text {Rosa/+ }}$, miR-276a $a^{D 8 /+}$, and miR-276a ${ }^{D 8 / R o s a}$ animals. n.S., not significant; $N=4$. $\boldsymbol{H}$, Two precise excision alleles, miR-276a $a^{A 6}$ and miR-276a $a^{D 2.2}$, can reverse the olfactory avoidance defect seen in miR-276a $a^{R o s a / D 8}$ mutant animals. ${ }^{*} p<0.05 ; N=6 . I$, Olfactory avoidance tests with $\mathrm{MCH}, 0 \mathrm{CT}$, and BA at various concentrations for WT, miR-276a ${ }^{\text {Rosa/+ }}$, miR-276a $a^{D 8 /+}$, and miR-276a ${ }^{D 8 / R o s a}$ animals. $N=\sim 6-10$. avoidance responses to $\mathrm{MCH}$ (Fig. $1 H ; F_{(5,30)}=16.96, p<0.05$ ). We next tested whether transgenes containing genomic BAC clones are sufficient to rescue the naive olfactory response defects (Fig. 2). All three BAC clones tested include the predicted miR$276 a$ precursor region but exclude any other protein coding genes 
A

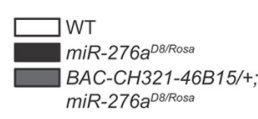

B
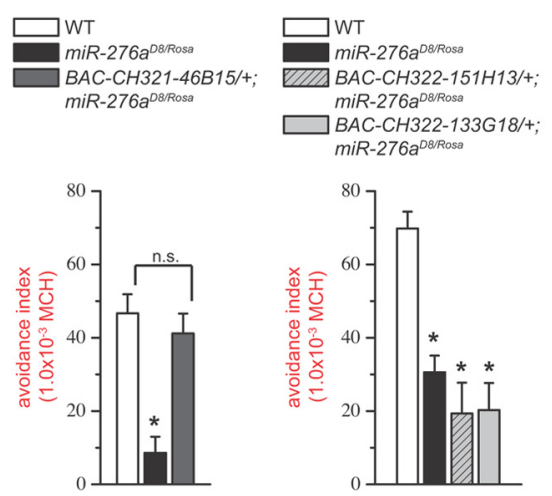

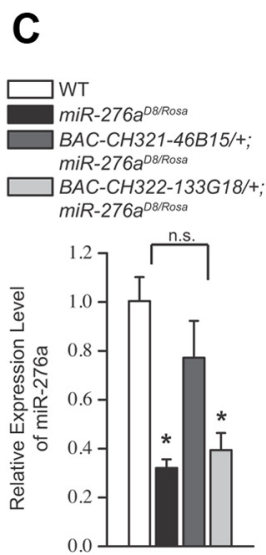

Figure 2. Transgene rescue of miR-276a mutants. $A$, A copy of $\sim 75 \mathrm{~kb} B A C$ rescue clone CH321-46B15 fully rescues the olfactory avoidance behavior defect in miR-276a $a^{D 8 / R o s a}$ mutant animals. ${ }^{*} p<0.05 ; N=\sim 12-16 . B$, The two $\sim 20 \mathrm{~kb} B A C$ rescue clones, $\mathrm{CH} 322-151 \mathrm{H} 13$ and CH322-133G18, failed to rescue the olfactory avoidance defect in miR-276a $a^{D 8 / R o s a}$ mutant animals. ${ }^{*} p<0.05 ; N=4$. C, Expression levels of miR-276 are restored with the $\sim 75 \mathrm{~kb} \mathrm{BAC}$ CH321-46B15 but not with the $\sim 20 \mathrm{~kb} \mathrm{BAC} \mathrm{CH322-133G18.}{ }^{*} p<0.05$; n.s., not significant; $N=4-8$.

or miR-276b coding region (Fig. $1 A$ ). We found that the expression levels and behavioral defect of $m i R-276 a^{D 8 / R o s a}$ can be fully rescued by providing a transgenic copy of a $\sim 75 \mathrm{~kb}$ BAC clone $\mathrm{CH} 321-46 \mathrm{~B} 15$ (Fig. $2 A, F_{(2,35)}=5.49, p<0.05$ ). In contrast, smaller BAC clones $(\sim 20 \mathrm{~kb}$ CH322-133G18 and $\sim 19 \mathrm{~kb}$ CH322-151H13) (Fig. $1 A$ ) failed to rescue $m i R-276 a^{D 8 / R o s a}$ expression or olfactory behavior (Fig. $2 B ; F_{(3,12)}=13.42, p<0.05$ ). Together, the above findings provide convergent evidence that miR$276 \mathrm{a}$ is responsible for the defect in naive odor responses.

\section{Dominant negative miRNA “sponge" phenocopies naive olfactory response defect of $m i R-276 a$ mutants}

As a complementary and independent approach, we made use of the miRNA "sponge" system (Ebert et al., 2007), which was recently adapted to the Drosophila model (Loya et al., 2009). The "sponge" transgenes include 10 repetitive sequences complementary to miR-276a with mismatches at positions 9-12 for enhanced stability. When UAS::EGFP::miR-276aSPONGE expression is induced by GAL4, endogenous miR-276a should be "soaked up" and its normal function should be interfered with (Fig. 3A). As controls, we used UAS::EGFP::SCRAMBLED flies in which 10 repetitive complementary sequences are replaced by a scrambled sequence not recognized by any miRNA in Drosophila. We demonstrated the efficiency and specificity of this approach with an in vivo assay in which expression of UAS::EGFP::miR-276aSPONGE can suppress the developmental lethality from pan-neuronal overexpression of miR-276a (Fig. $3 B$ ). We next tested naive olfactory avoidance behavior in animals expressing UAS::EGFP::miR-276aSPONGE or UAS::EGFP:: $S C R A M B L E D$ under the pan-neuronal elav-GAL4 driver (Fig. $3 E$ ). We used two independent transgenic lines each for UAS::EGFP:: miR-276aSPONGE and UAS:: EGFP::miR-SCRAMBLED. We found that expression of the UAS::EGFP::miR-276aSPONGE in neurons impaired the animals' performance in the naive olfactory avoidance assay, while animals that express the UAS::EGFP::SCRAMBLED transgenes performed normally (Fig. $3 E ; F_{(5,42)}=24.48, p<0.05$ ). The control animals that contained the UAS-transgenes but not the Gal4 driver performed normally as well (Fig. $3 F ; F_{(4,25)}=0.75$, not significant).

In addition to recapitulating the mutant phenotype, the "sponge" system also provided an indirect observation of miR- 276a expression pattern. Because endogenous miR-276a can bind to the $3^{\prime}$ UTR of the UAS::EGFP::miR-276aSPONGE transgene, expression of EGFP driven from the pan-neuronal elav-GAL4 was dramatically reduced when compared with that of UAS::EGFP::SCRAMBLED. This is consistent with the idea that miR-276a is broadly expressed in adult fly heads (Fig. $3 C, D$ ).

\section{Postdevelopment function of miR-276a is sufficient for naive olfactory responses}

To define the temporal requirements for miR-276a function, we combined a tubulin promoter driven GAL80 temperature-sensitive $\left(G A L 80^{t s}\right)$ transgene (McGuire et al., 2004) with elav-GAL4. GAL $80^{\text {ts }}$ is a suppressor of GAL4 and, at the permissive temperature $\left(18^{\circ} \mathrm{C}\right)$, GAL $80^{\text {ts }}$ is active and suppresses GAL4-controlled UAS::EGFP::miR-276aSPONGE transgene expression. At the restrictive temperature $\left(29^{\circ} \mathrm{C}\right), \mathrm{GAL} 80^{\mathrm{ts}}$ is inactivated, and the SPONGE or SCRAMBLED transgenes are expressed. We crossed either UAS::EGFP::miR-276aSPONGE or UAS::EGFP:: $S C R A M B L E D$ transgenic flies to elav;GAL80 ${ }^{t s}$ animals. Progeny from these crosses were kept at the restrictive temperature $\left(29^{\circ} \mathrm{C}\right)$. Hence transgene expression was kept on, and miR-276a function was blocked during development. After eclosion, we separated the progeny of each cross into two groups: one was continuously incubated at the restrictive temperature $\left(29^{\circ} \mathrm{C}\right)$, where miR-276a function is disrupted, and the other one was shifted to the permissive temperature $\left(18^{\circ} \mathrm{C}\right)$, allowing $\mathrm{miR}-276$ a function to be turned back on. Both groups were incubated for an additional $72 \mathrm{~h}$ before being tested for avoidance behavior (Fig. $3 G$ ). We found that when miR-276a function was kept off after eclosion (no shift to permissive temperature), the flies that contained UAS::EGFP::miR276aSPONGE transgenes exhibited reduced naive odor avoidance compared with UAS::EGFP::SCRAMBLED and elav/+; GAL80 $80^{t s} /+$ control animals. This was true for each of the two independent "sponges" versus "scrambled" transgenes. In contrast, when the UAS::EGFP::miR-276aSPONGE transgene was turned off after development (permitting a recovery of miR-276a function), we observed a significant restoration of naive olfactory avoidance in the temperature-shifted group (Fig. 3G; SPONGE\#1, $t_{(22)}=4.65, p<$ 0.05 ; SPONGE\#2, $\left.t_{(22)}=2.71, p<0.05\right)$. In control crosses with the $U A S:: E G F P:: S C R A M B L E D$ transgenes, there was no significant difference between temperature-shifted and temperature-unshifted groups (Fig. 3G; SCRAMBLED\#1, $t_{(6)}=0.73$, not significant; $S C R A M B L E D \# 4, t_{(6)}=0.68$, not significant). These findings demonstrate that acute (postdevelopmental) function of miR-276a is sufficient for normal naive odor avoidance. Thus this behavioral effect is unlikely to derive from defects in neural development.

\section{miR-276a is required in $\mathrm{EB}$ neurons for normal naive olfactory responses to $\mathrm{MCH}$}

To map the neural cell types in which miR-276a function is required, we conducted a small-scale screen in which the UAS::EGFP:: miR-276aSPONGE was tested in combination with a set of GAL4 lines that each interrogate distinct subsets of the known circuits that underlie either olfaction or olfactory memory. Because some of these GAL4 lines may drive modest levels of expression, we combined the two UAS::EGFP::miR-276aSPONGE transformant lines to increase the levels of transgene expression (Loya et al., 2009). We selected GAL4 lines that express in olfactory sensory neurons (Or83b), antenna lobe projection neurons (GH146), antenna lobe local interneurons (GH298), MBs (OK107 and c747), and two different sets of EB neurons (c232 and c547) (Fig. $3 \mathrm{H}, \mathrm{I}$ ). In each case, we tested naive olfactory responses to $\mathrm{MCH}$ in animals that contained both the GAL4 driver and two UAS::EGFP::miR-276aSPONGE trans- 
A

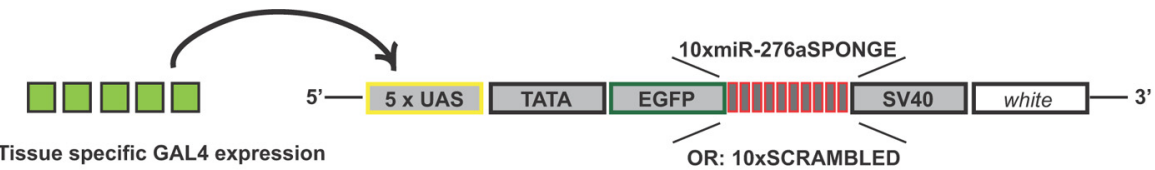

B
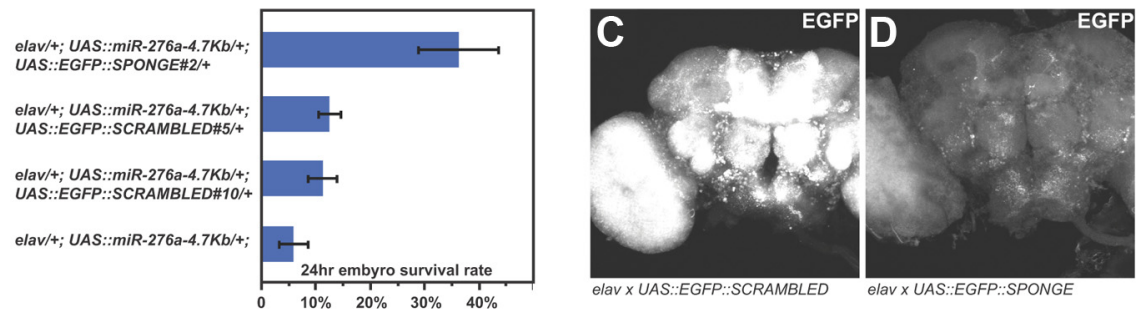

E

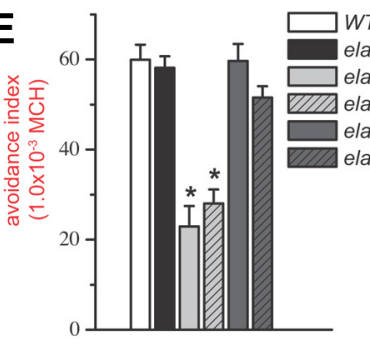

$W T$

lav/t+

UAP $/:$ SPONGE\#1/+

IIV/+, +/+; UAS::EGFP::SPONGE\#2/+

+; UAS.:EGFP::SCRAMBLED\#4/+

G
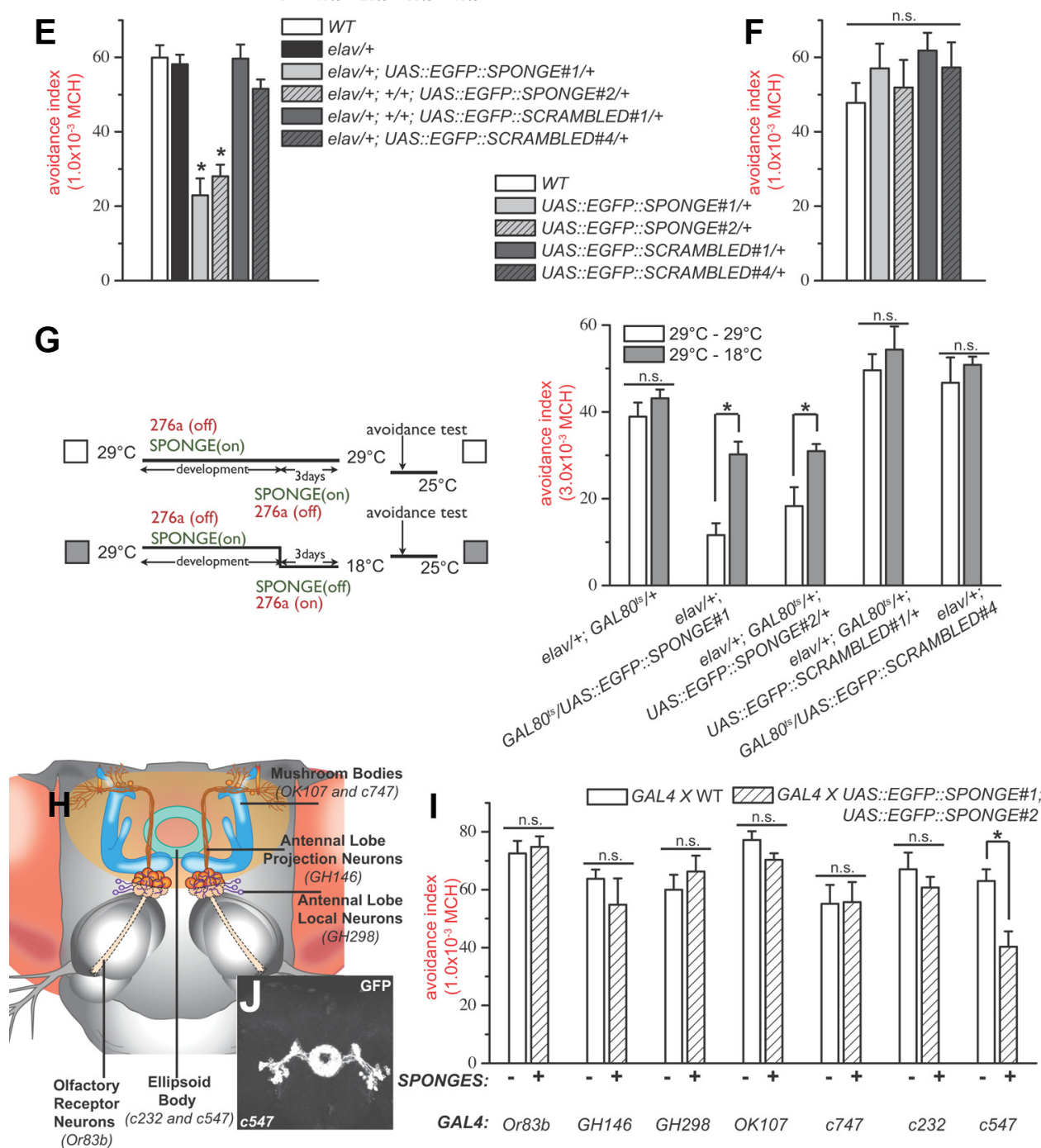

Figure 3. Postdevelopment miR-276a function in EB neurons for naive olfactory responses. $\boldsymbol{A}-\boldsymbol{D}$, The inducible miRNA "sponge" system in Drosophila is illustrated (Loya et al., 2009) (A). Quantification of early embryo hatching rate from crossing UAS:::miR-276a-4.7Kb transgene to elav with or without UAS::EGFP::miR-276aSPONGE indicated that the miR-276a "sponge" can efficiently "soak up" excessive miR-276a (B). "Sponge" as a sensor to report endogenous brain expression of miR-276a. EGFP expression in a representative brain from the progeny of crossing elav to UAS::EGFP::SCRAMBLED $(\boldsymbol{C})$ and EGFP expression in a representative brain from the progeny of crossing elav to UAS:::EGFP:::miR-276aSPONGE (D). $\boldsymbol{E}, \boldsymbol{F}$, Neuronal expression of UAS::EGFP:::miR-276aSPONGE with elav GAL4 causes a similar behavior defect, as observed in miR-276a mutant animal, and expression of control UAS::EGFP::SCRAMBLED transgenes does not affect olfactory avoidance $\left(\boldsymbol{E}_{*}^{*} p<0.05 ; N=8\right)$. Animals heterozygous for each transgene exhibit normal olfactory avoidance behavior $(\boldsymbol{F} ; \mathrm{n} . \mathrm{s}$., not significant; $N=6) . \mathbf{G}$, Postdevelopment expression of miR-276a is sufficient to restore normal naive olfactory avoidance. Temperature-shift induction scheme is illustrated (left; for detail, see Results and Materials and Methods). 0 lfactory avoidance was partially rescued when miR-276a function was turned on postdevelopmentally (right; ${ }^{*} p<0.05$; n.S., not significant; $N=\sim 4-12$ ). $H-J$, To map the circuitry where miR-276a is required for naive olfactory avoidance, UAS::EGFP::miR-276aSPONGE transgenes were expressed with a collection of GAL4 lines (Or83b, GH146, GH298, OK107, C747, C232, and (547), each of which label defined cell types that make up the Drosophila olfaction or olfactory memory circuit $(\boldsymbol{H})$. Expression of UAS.::EGFP::miR276aSPONGE transgenes with $c 547$ GAL4, which labels the R2/4m neurons in EB, phenocopies the naive olfactory avoidance defect observed in miR-276a mutant animals $\left(\boldsymbol{I} ;{ }^{*} p<0.05 ; \mathrm{N}=8\right)$. In contrast, other cell types did not affect this olfactory behavior $(\boldsymbol{I} ; \mathrm{n} . \mathrm{s}$, not significant; $N=4)$. c547 expression pattern is demonstrated in $J$. 
A

\begin{tabular}{|c|c|c|c|c|c|c|}
\hline gene & $\begin{array}{l}\text { Pictar } \\
\text { Rank\# }\end{array}$ & $\begin{array}{l}\text { TargetScanFly } 6.0 \\
\text { \# of conserved site }\end{array}$ & $\begin{array}{l}\text { EIMMO } \\
\text { Rank\# }\end{array}$ & $\begin{array}{l}\text { miRanda } \\
\text { Rank\# }\end{array}$ & $\begin{array}{l}\text { expression pattern } \\
\text { in adult head }\end{array}$ & function \\
\hline$z f h 2$ & 1 & 3 & 1 & 1 & Unknown & nervous system development \\
\hline$d p r$ & 3 & not predicted & 2 & $>50$ & Gustatory Organ & salt aversion response \\
\hline DopR & 5 & 1 & 14 & $>50$ & $\begin{array}{l}\text { Mushroom Body } \\
\text { Central Complex }\end{array}$ & $\begin{array}{l}\text { olfactory learning and memory } \\
\text { various forms of arousal }\end{array}$ \\
\hline Pino & 11 & 1 & $>50$ & 2 & Antenna & olfactory avoidance \\
\hline Nf1 & 17 & 1 & 22 & $>50$ & Broad & olfactory learning and memory \\
\hline
\end{tabular}

B

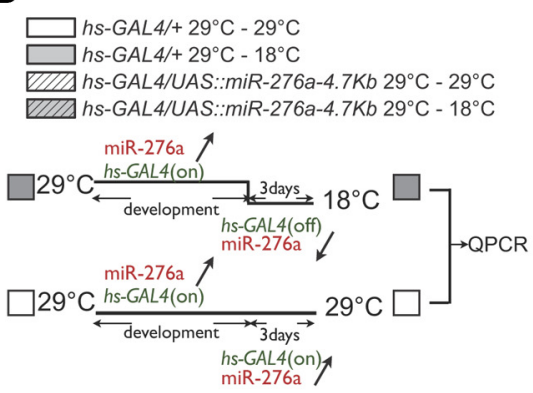

C

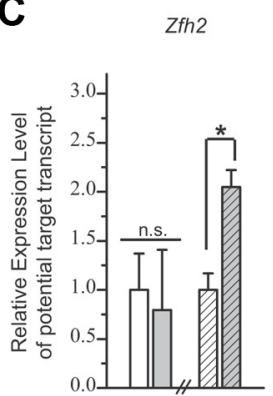

D
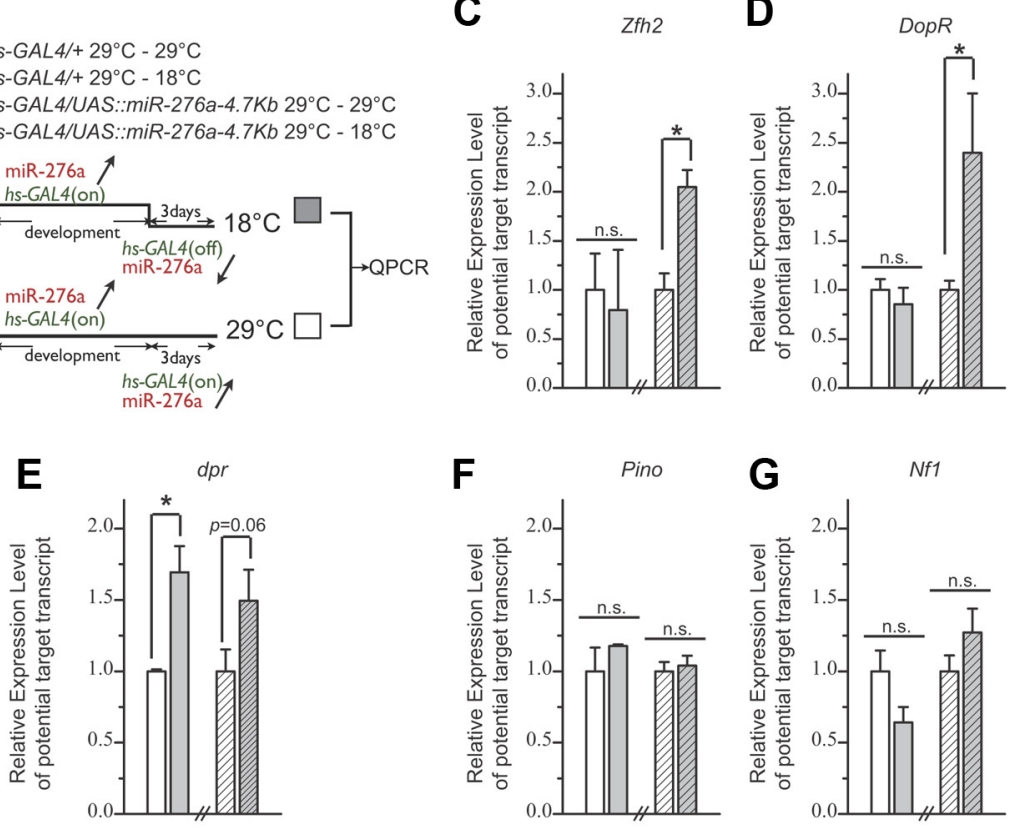

H
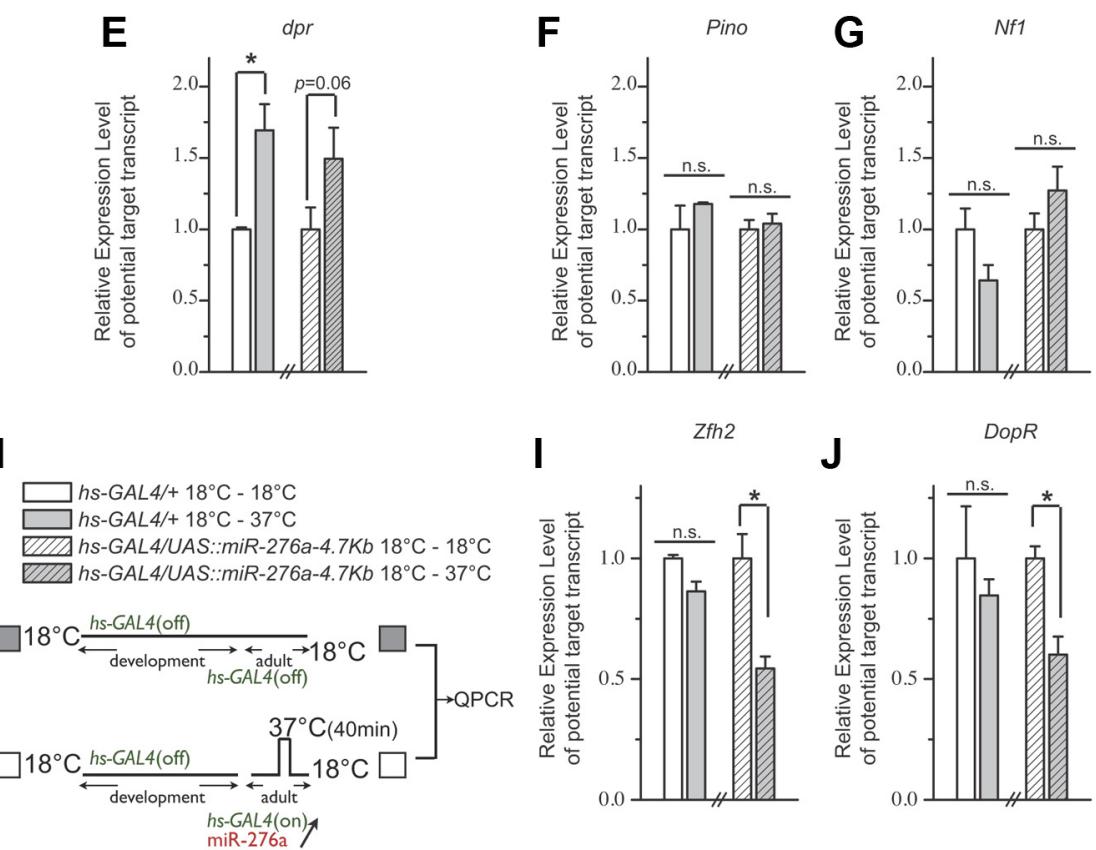

\section{J}

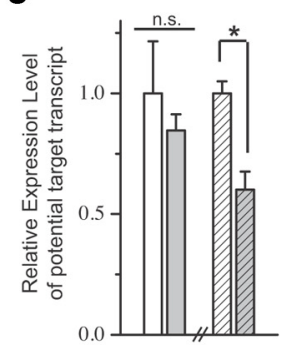

Figure 4. miR-276a regulates DopR expression level. $\boldsymbol{A}$, miR-276a target prediction was obtained from four published methods: Pictar, TargetScan, ElMMo, and miRanda (Pictar: http://pictar.mdc-berlin.de/; TargetScanFly6.0: http://www.targetscan.org/fly/; EIMMo: http://www.mirz.unibas.ch/EIMMo2/; and miRanda: http://www.microrna.org/microrna/home.do) (Enright et al., 2003; Grün et al., 2005; Gaidatzis et al., 2007; Ruby et al., 2007; Betel et al., 2010). We selected several targets with known neuronal or olfactory functions, including zfh2, dpr, DopR, Pino, and Nf1 (Nakamura et al., 2002; Rollmann et al., 2005; Kim et al., 2007b; Andretic et al., 2008; Lebestky et al., 2009; Kong et al., 2010; Qin et al., 2012). B-G, To test whether the predicted target gene expression is regulated by miR-276a, we used a heat-inducible $h$ S-GAL4 line in combination with a UAS::miR-276a-4.7Kb transgene to overexpress miR-276a. Because high level of neuronal expression through development is lethal (Fig. 3B), we used a mildtemperature regime ( $\boldsymbol{B}$; see Results and Materials and Methods) to provide a less severe heat induction during development. We then tested the effects on target gene transcript levels by shifting animals to lower temperature postdevelopment. In the temperature-shifted groups $\left(29\right.$ to $\left.18^{\circ} \mathrm{C}\right)$ we see significantly induced levels of target transcript levels for $Z$ fh 2 and $D o p R$, compared with groups maintained at $29^{\circ} \mathrm{C}\left(\boldsymbol{C}\right.$ and $\left.\boldsymbol{D} ;{ }^{*} p<0.05 ; N=\sim 2-3\right)$. Transcript levels of $Z$ fh 2 and $D o p R$ were not affected by the temperature shift in control hs-GAL4/+ animals (C and D; n.S., not significant; $N=\sim 2-3$ ). With $d p r$, we observed induction in temperature-shifted groups for both $h s-G A L 4 / U A S:: m i R-276 a-4.7 K b$ and $h s-G A L 4 /+$ animals, indicating temperature shift, but not miR-276a, can alter dpr expression levels ( $\left.\boldsymbol{E}_{;}^{*} p<0.05 ; N=\sim 2-3\right)$. For Pino and Nf1, no change in transcript levels was observed for any genotype or treatment ( $\boldsymbol{F}$ and $\boldsymbol{G} ;$ n.S., not significant; $N=\sim 2-3$ ). $\boldsymbol{H}-\boldsymbol{J}$, Another temperature-shift regimen was also used to test whether miR-276a regulates $Z f h 2$ and DopR gene expression $(\boldsymbol{H})$. Forty-minute heat-shock induction of miR-276a expression at $37^{\circ} \mathrm{C}$ in adult hs-GAL4/UAS::miR-276a-4.7Kb animals caused a significant downregulation of transcript levels of $Z f h 2$ and $D o p R$, which are predicted to be targets of miR-276a ( $I$ and $J ;{ }^{*} p<0.05$; n.S., not significant; $N=3$ ).

genes in comparison with controls heterozygous for the GAL4 drivers. Surprisingly, the collection of GAL4 lines (Or83b, GH146, GH298, OK107, and c747) that query the main olfactory system from olfactory receptor neurons to MBs yielded normal naive olfactory avoidance behavior (Fig. 3 I; Or83b, $t_{(6)}=0.39$, not significant; $G H 146, t_{(6)}=0.93$, not significant; GH298, $t_{(6)}=0.84$, not significant; $O K 107, t_{(6)}=$ 1.81 , not significant; $c 747, t_{(6)}=0.06$, not significant). In contrast, only $c 547$, which labels the R2/R4m subset of neurons in the EB (Fig. $3 J$ ), showed significantly reduced naive olfactory avoidance of $\mathrm{MCH}$ (Fig. $3 I$; $t_{(14)}=$ 3.37, $p<0.05$ ). c232, which labels R3/R4d EB neurons, did not affect olfactory avoidance (Fig. 3I; c232, $t_{(6)}=0.92$, not significant). The finding with c547-labeled R2/ $\mathrm{R} 4 \mathrm{~m}$ neurons was unexpected because EB neurons are several synapses downstream of the primary circuits thought to code for olfactory stimuli (Chiang et al., 2011) (FlyCircuit Database: http://www.flycircuit.tw). Several studies, however, have linked EB neurons to long-term olfactory memory (Wu et al., 2007) and arousal to external stimuli (Lebestky et al., 2009; Kong et al., 2010). The arousal phenotypes of mutations in a $D o p R$ gene are of particular relevance because they can be fully rescued by DopR expression using the c547 GAL4 but not c232 GAL4 (Lebestky et al., 2009; Kong et al., 2010). The requirement for miR-276a function in $\mathrm{R} 2 / \mathrm{R} 4 \mathrm{~m}$ EB neurons thus guided our search for functional targets of miR-276a.

\section{miR-276a impact on naive avoidance of} MCH is mediated by DopR

We used four published methods (Pictar: http://pictar.mdc-berlin.de/; TargetScan Fly6.0: http://www.targetscan.org/fly/; ElMMo: http://www.mirz.unibas.ch/ ElMMo2/; and miRanda: http://www. microrna.org/microrna/home.do) (Enright et al., 2003; Grün et al., 2005; Ruby et al., 2007; Gaidatzis et al., 2007; Betel et al., 2010) to predict mRNA targets of miR-276a and obtained a list of predicted target genes that we prioritized based on prediction scores from each method, known nervous system expression patterns, and neuronal or behavioral functions (Fig. 4A). We focused on the following genes: $\mathrm{Zn}$ finger homeodomain 2 (zfh2), defective proboscis extension response $(d p r)$, DopR, Pinocchio (Pino; also known as smi21F, smell impaired 21F). and Neurofibromin 1 (Nf1). These predicted target genes have high ranking scores with all prediction methods and have established functions related to nervous system development (Lundell and Hirsh, 1992), regulating arousal (Andretic et al., 2008; Lebestky et al., 
2009; Kong et al., 2010), mediating olfactory responses (Nakamura et al., 2002; Rollmann et al., 2005), and olfactory learning and memory (Kim et al., 2007a; Qin et al., 2012). We tested whether reducing miR-276a expression can acutely alter predicted target gene expression. We crossed a heatshock GAL4 ( $h s-G A L 4)$ driver to a UAS::miR-276a-4.7Kb transgene to overexpress miR-276a through development at $29^{\circ} \mathrm{C}$, at which temperature $h s-G A L 4$ has leaky expression (Xia et al., 2005). After eclosion, we separated the progeny into two groups: one was continuously incubated at $29^{\circ} \mathrm{C}$, and the other was incubated at $18^{\circ} \mathrm{C}$ to reduce heatshock-driven expression (Fig. 4B). hs-GAL4/+ heterozygous animals were used as a control. We used QPCR to compare the expression levels of each candidate target gene in heads from animals that had been kept at $29^{\circ} \mathrm{C}$ with those that had been shifted to $18^{\circ} \mathrm{C}$ to reduce the transgenic expression of miR-276a. In the case of $Z f h 2$ and DopR, we observed a significant increase in expression levels when the miR-276a transgene was silenced (Fig. $4 C, D ; C, t_{(4)}=4.32, p<0.05 ; D, t_{(4)}=2.27$, $p<0.05)$. With Pino and Nf1, no change in expression was detected (Fig. $4 F, G$; not significant). With $d p r$, we saw a trend of increased expression in both the $h s-G A L 4 / U A S:: m i R-276 a-4.7 \mathrm{~Kb}$ and the $h s-G A L 4 /+$ control genotypes, indicating that temperature shift on its own can affect $d p r$ expression levels (Fig. $4 E ; t_{(3)}=5.03$, $p=0.02 ; t_{(4)}=1.85, p=0.06$ ). Thus, two of five tested candidates showed miR-276a-dependent changes in transcript levels (see below for protein level). The increased expression of $Z$ fh 2 and $D o p R$ when the miR-276a transgene is turned off supports the idea that the miRNA normally represses these two genes. As a second test of this regulatory relationship, we used an acute induction protocol in which the heatshock-driven $m i R-276 a$ transgene was kept off $\left(18^{\circ} \mathrm{C}\right)$ during development and then acutely induced with a $40 \mathrm{~min}$ heat shift $\left(37^{\circ} \mathrm{C}\right)$ followed by $4 \mathrm{~h}$ recovery. With this acute induction protocol (Fig. $4 H$ ), both $Z f h 2$ and DopR levels were decreased (Fig. 4I,J; $I, t_{(4)}=4.07, p<0.05$; J, $\left.t_{(4)}=4.46, p<0.05\right)$.

The DopR 3'UTR contains at least one putative miR-276a binding site, which is highly conserved across Drosophila species (Fig. 5A). While we cannot be certain that the effects on DopR are direct and mediated by the putative target motif, we do observe a negative regulatory effect of miR-276a on DopR expression as predicted for a direct target. In either case, the negative sign of interaction predicts that mutation of $m i R$ $276 a$ would cause increased DopR expression. This idea was of particular interest because of our finding that miR-276a functions within R2/R4m EB neurons labeled by c547. DopR function within these neurons has an established role in two different forms of arousal (Lebestky et al., 2009; Kong et al., 2010) and the DopR mutations exhibit a dominant increase in arousal, suggesting dosage sensitivity (Lebestky et al., 2009). In our case, mutations of miR-276a would lead to increased DopR expression, which should cause decreased arousal. We therefore tested whether reducing the copy number of DopR can suppress miR-276a mutations. We introduced a copy of the DopR $R^{\text {dumb2 }}$ allele into the $m i R-276 a^{\text {D8/Rosa }}$ mutant and tested naive olfactory avoidance. Remarkably, the Dop $R^{d u m b 2 /+}$, miR-276a $a^{\text {D8/Rosa }}$ animals exhibited normal avoidance (Fig. $5 B$; $\left.F_{(2,29)}=23.55, p<0.05\right)$. Together with the expression studies described above, this experiment provides strong evidence that $\operatorname{DopR}$ is a functional downstream effector of miR-276a within $\mathrm{R} 2 / \mathrm{R} 4 \mathrm{~m}$ EB neurons and that this regulatory relationship affects naive responses to this olfactory stimulus.
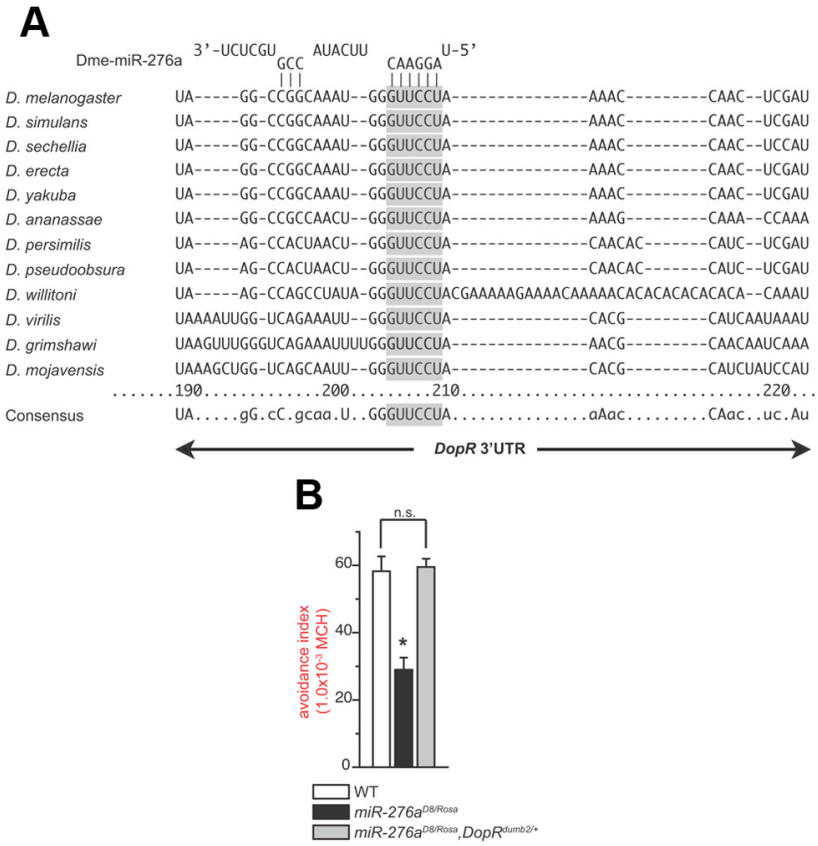

Figure 5. DopR is a downstream target of miR-276a for naive olfactory responses. $\boldsymbol{A}$, miR276a seed sequence recognizes a highly conserved 6 nt target site in the $3^{\prime}$ UTR of the DopR transcript. The predicted miR-276a-binding site (shaded boxes) is conserved within the $3^{\prime}$ UTR sequences of DopR transcripts from 12 different Drosophila species (TargetScanFly6.0). B, Removing a copy of DopR gene by introducing a strong hypomorphic allele of Dop $R$ (the $D o p R^{\text {dumb2 }}$ allele) was sufficient to fully suppress the naive olfactory avoidance defect in miR-276a $a^{D 8 / R o s a}$ mutant animals. ${ }^{*} p<0.05$; n.S., not significant; $N=\sim 8-16$.

\section{miR-276a impacts olfactory LTM via effects on DopR expression in MBs}

In addition to EB, DopR also is expressed in MB (Kim et al., 2007a; Lebestky et al., 2009; Fig. 6A, B), the main anatomical structure underlying olfactory memory and learning in Drosophila. Mutations in the DopR gene can abolish short-term memory and LTM and restoring DopR expression in the $\gamma$-neuron subset of MB is sufficient to rescue both short-term memory and LTM (Kim et al., 2007a; Lebestky et al., 2009; Qin et al., 2012). We therefore wondered whether the same $m i R-276 a:: D o p R$ regulatory relationship in EB also occurs in $\mathrm{MB}$ to modulate DopR expression levels. We examined DopR expression levels by immunohistochemistry in brains where UAS::EGFP::miR-276aSPONGE is expressed in OK107-labeled MB neurons. We found that there is indeed a substantial elevation of DopR expression in $\mathrm{MB}$ when we drive the "sponge" transgene in $\mathrm{MB}$ compared with control animals (UAS::EGFP:: miR-276aSPONGE/+ heterozygous animals) (Fig. 6C,D). These results are consistent with the effects on DopR expression observed with QPCR (Fig. 4).

The finding that miR-276a regulates DopR in MB suggests a role in olfactory memory. In the case of the $m i R-276 a^{D 8 / R o s a}$ mutant animals, the defect in naive odor responses precluded drawing conclusions about memory performance per se because the conditioning process involves responses to these same odors. But the differing effects on naive odor avoidance of cell type-specific "sponge" expression in $\mathrm{EB}$ versus $\mathrm{MB}$ suggested that we might be able to separate effects on memory from those on naive odor responses. Expression of the UAS::EGFP:: $m i R-276 a S P O N G E$ in MB using GAL4 driver line OK107 in fact did not cause defects in naive olfactory avoidance to any of the three odors tested or to shock avoidance (Figs. 3I, 6I; BA, $F_{(2,9)}=2.13$, not significant; OCT, $F_{(2,9)}=0.47$, not significant; shock, $F_{(2,19)}=0.39$, not significant). Because odor avoidance and 

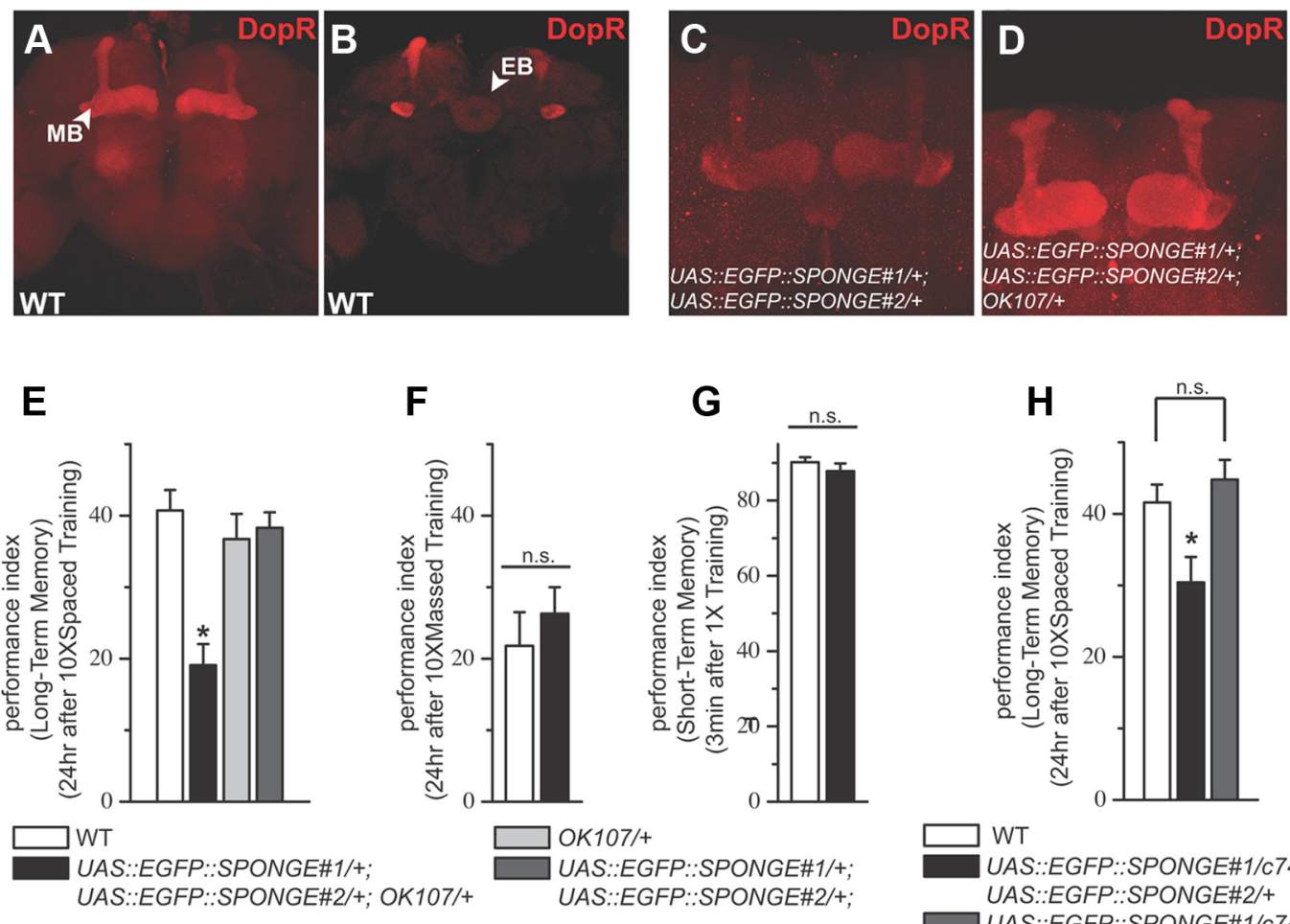

\begin{tabular}{l|c|c|c}
\multirow{2}{*}{ I } & \multicolumn{2}{|c|}{ Olfactory Acuity } & $\begin{array}{c}\text { Shock } \\
\text { Reactivity }\end{array}$ \\
\cline { 2 - 4 } & $\begin{array}{c}\text { BA } \\
0.5 \times 10^{-3} \mathrm{v} / \mathrm{v}\end{array}$ & $\begin{array}{c}\text { OCT } \\
1.5 \times 10^{-3} \mathrm{v} / \mathrm{v}\end{array}$ & 60 volts \\
\hline $\begin{array}{l}\text { UAS::EGFP::SPONGE\#1/+; } \\
\text { UAS::EGFP::SPONGE\#2/+ }\end{array}$ & $28.61 \pm 4.17$ & $50.85 \pm 2.58$ & $54.07 \pm 5.05$ \\
\hline OK107/+ & $18.36 \pm 3.36$ & $45.64 \pm 9.11$ & $47.06 \pm 7.39$ \\
\hline $\begin{array}{l}\text { UAS::EGFP::SPONGE\#1/+; } \\
\text { UAS::EGFP::SPONGE\#2/+;OK107/+ }\end{array}$ & $20.57 \pm 3.51$ & $55.15 \pm 7.38$ & $45.26 \pm 7.50$
\end{tabular}

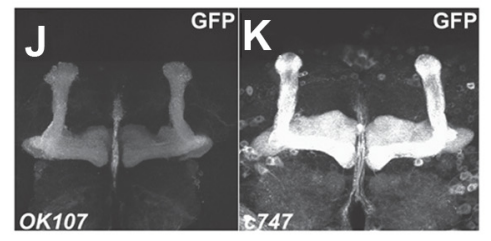

M
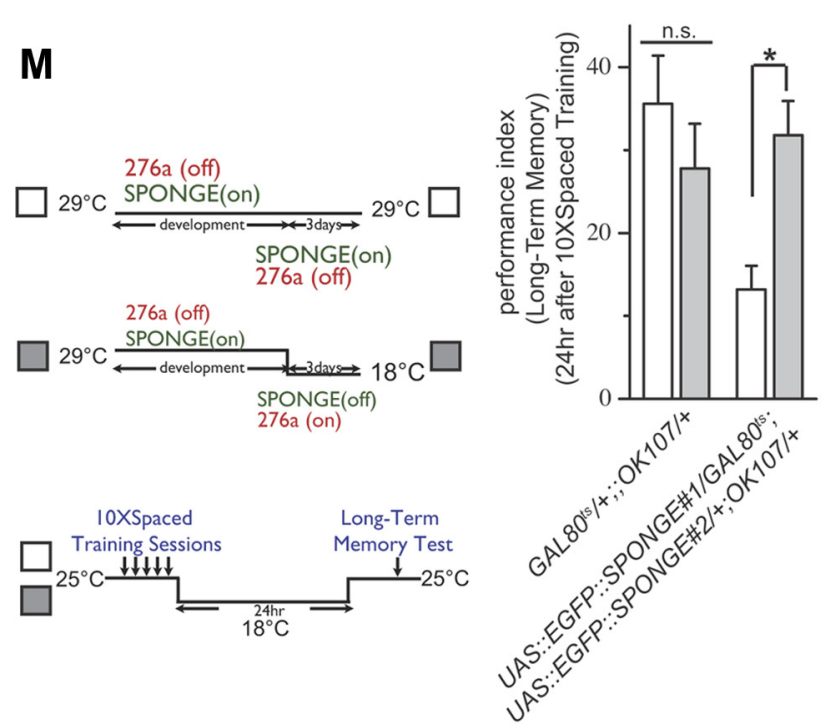

Figure 6. miR-276a regulates DopR in MB for LTM. A, B, DopR expresses in MBs and EB of the fly brain. C, D, Expression of UAS::EGFP:::miR276aSPONGE transgenes with MB GAL4 line OK107 results in elevated DopR expression in MB (D compared with $\boldsymbol{C}$. Immunohistochemistry for control $(\boldsymbol{C})$ and experimental $(\boldsymbol{D})$ brains were performed in parallel and images were taken at identical confocal settings. E-J, Expression of UAS::EGFP::miR276aSPONGE transgenes with MB GAL4 line $0 K 107$ causes impaired LTM performance compared with WT and heterozygous controls $\left(\boldsymbol{E} ;{ }^{*} p<0.05 ; N=\right.$ 8). In contrast, memory measured $24 \mathrm{~h}$ after 10 massed training sessions $(\boldsymbol{F})$ or short-term memory measured 3 min after a single training session $(\boldsymbol{G})$ each appeared normal $(\boldsymbol{F} ; \mathrm{n} . \mathrm{s}$, not significant; $N=7 ; G$, n.S., not significant; $N=8$ ). As with the OK107 GAL4 line, expression of UAS::EGFP:::miR276aSPONGE with C747, a second MB-expressing GAL4 line resulted in significantly impaired LTM performance. The LTM defect can be fully suppressed in the presence of one copy of $D o p R^{d u m b 1}$ strong mutant allele $\left(\boldsymbol{H} ;{ }^{*} p<0.05 ;\right.$ n.s., not significant; $\left.N=14\right)$. Olfactory acuity and shock reactivity appeared normal when UAS::EGFP::miR276aSPONGE transgenes were expressed with OK107 ( $\boldsymbol{I}$ n.s. not significant; $N=4-8) .0 K 107$ and $c 747$ expression patterns are shown in $\boldsymbol{J}$ and $\boldsymbol{K}$. $\boldsymbol{L}$, A PiggyBac (PBac) insertion within DopR produces the Dop $R^{\text {dumb2 } 2}$ allele, which is defective in forming $\left.\mathrm{LTM}^{*}{ }^{*} p<0.05 ; \mathrm{N}=8\right)$. This PBac insertion contains a UAS-enhancer element (Figure legend continues.) 
shock reactivity were normal with miR-276a "sponge" expression in $\mathrm{MB}$, it provided a means to test the role in memory in a meaningful way without the caveats that come with defects in task-relevant sensorimotor responses. We therefore tested the effects on memory and learning of expressing the sponge in MB with two GAL4 lines (Fig. $6 E-H, J, K)$. Although responses to all three odors tested appear normal with MB-driven "sponge" expression, we selected OCT and BA for these discriminative olfactory conditioning experiments because the naive response defects to these odors are mild compared with $\mathrm{MCH}$ even for the case where miR-276a function is compromised in the whole animal (Fig. 1I). With the OK107 GAL4 line, we observed a significantly reduced memory performance measured $24 \mathrm{~h}$ after spaced repetitive training (LTM) (Fig. $\left.6 E ; F_{(3,28)}=11.49, p<0.05\right)$ but not after repetitive massed training or immediately after one training session (Fig. $6 F, G ; F, t_{(12)}=0.08$, not significant; $G, t_{(16)}=2.67$, not significant). Thus, the defect appears specific to LTM, which requires new protein synthesis (Tully et al., 1994). LTM is similarly reduced with GAL4 line c747, which also labels $\mathrm{MB}$ neurons (Fig. $6 H ; F_{(2,39)}=6.60$, $p<0.05)$.

We wondered whether miR-276a function in MB for LTM is mediated by regulation of $D o p R$ expression, as was the case in EB for naive olfactory responses to $\mathrm{MCH}$. We introduced a copy of a strong DopR allele into animals that also express UAS::EGFP::miR-276aSPONGE in MB. Because this experiment made use of GAL4 to drive the sponge transgene, we used the $D o p R^{d u m b 1}$ allele rather than $D o p R^{d u m b 2}$ because the latter allele contains a GAL4-responsive UAS element upstream of the DopR coding region (see below). We found that removing one copy of the DopR gene was sufficient to fully suppress the effects on olfactory memory caused by expressing the dominant negative miR-276a "sponge." The defective LTM observed in UAS:: EGFP::SPONGE\#1/c747; UAS::EGFP::SPONGE\#2/+ animals is fully reversed in UAS::EGFP::SPONGE\#1/c747; UAS::EGFP:: SPONGE\#2/+, DopR $R^{\text {dumb1/+ }}$ animals (Fig. $6 H$ ). This experiment is consistent with the idea that miR-276a normally holds DopR levels in check within MB. When the miRNA function is reduced, DopR levels increase (Figs. 4, 5, 6C,D), and removing one copy of the DopR gene suppresses the effect. A prediction of this dosage sensitivity hypothesis is that overexpression of DopR in MB above and beyond the levels normally seen also should compromise LTM. To test this idea, we compared the effects on LTM of expressing three different levels of DopR in MB. First, the $D o p R^{d u m b 2}$ homozygous mutation has very little expression of DopR and results in profoundly deficient LTM performance

\section{$\leftarrow$}

(Figure legend continued.) that can drive DopR expression when Gal4 is present. Expression of DopR in OK107-labeled MB neurons via the UAS element contained within this PBac is sufficient to restore both short-term memory and LTM (Qin et al., 2012). To investigate the effects of higher levels of overexpression of DopR in OK107-labeled MB neurons, we tested the effects of combined expression from an additional UAS::DopR transgene and the PBac insertion line. The addition of the UAS::DopR transgene results in LTM defect. ${ }^{*} p<0.05 ; N=8$. M, Postdevelopment induction of miR-276a function was accomplished with a GAL8Ots transgene. Animals were grown at $29^{\circ} \mathrm{C}$ to allow expression of the UAS::EGFP::miR276aSPONGE under control of the C747 GAL4 line. After development, animals were either maintained at $29^{\circ} \mathrm{C}$ or shifted to $18^{\circ} \mathrm{C}$ for $3 \mathrm{~d}$ to allow miR-276a function to return. Subsequent $10 \times$ spaced training sessions for LTM experiment were conducted at $25^{\circ} \mathrm{C}$. Trained animals were kept at $18^{\circ} \mathrm{C}$ before testing for $24 \mathrm{~h}$ memory at $25^{\circ} \mathrm{C}$ (left; for details, see Results and Materials and Methods). The LTM defect resulting from expression of UAS::EGFP::miR276aSPONGE can be fully restored in the temperature-shift group in which miR-276a function was turned back on postdevelopmentally. LTM performance was normal in control GAL8OS/ $/+$; $0 K 107 /+$ animals (right; ${ }^{*} p<0.05$; n.s., not significant; $N=8)$.
(Qin et al., 2012). The DopR $R^{\text {dumb2 }}$ allele is caused by insertion of a P-element in the upstream region (Kim et al., 2007b). Because this P-element contains a GAL4 responsive UAS enhancer, the memory defects can be rescued when combined with a strong MBGAL4 line, such as OK107, which drives expression of the flanking DopR gene on each of the two DopR ${ }^{\text {dumb2 }}$ alleles in the homozygous mutant (Kim et al., 2007b; Qin et al., 2012). To drive even higher levels of DopR within MB neurons, we tested the effects of adding a third UAS-responsive transgene (UAS::DopR). This results in an LTM defect that is as severe as that seen with the strong loss-of-function homozygous mutant (Fig. 6L; $\left.F_{(3,28)}=19.66, p<0.05\right)$.

\section{Acute function of miR-276a is sufficient for normal olfactory memory}

Postdevelopment function of miR-276a is sufficient to restore the naive olfactory response defect of $m i R-276 a$ mutant animals (Fig. $3 G)$. To test whether acute expression of miR-276a also is sufficient to restore normal LTM, we again introduced a copy of temperature-sensitive $G A L 80^{t s}$. Animals that contained the SPONGE transgenes, the OK107 GAL4 line, and the GAL80 (UAS::EGFP::SPONGE\#1/GAL80 $0^{\text {ts }}$; UAS::EGFP::SPONGE\#2/+; $O K 107 /+)$, and control groups that contained the $G A L 80^{t s}$ and the OK107 GAL4 line $\left(G A L 80^{t s} /+;\right.$ OK $\left.107 /+\right)$ were each raised at the restrictive temperature $\left(29^{\circ} \mathrm{C}\right)$ to keep the "sponge" transgene induced and the miR-276a function blocked in OK107-labeled MB neurons during development. After eclosion, we separated the progeny from each cross into two groups: one was continuously incubated at the restrictive temperature $\left(29^{\circ} \mathrm{C}\right)$ where miR276a function remained off in $\mathrm{MB}$, and the other one was incubated at the permissive temperature $\left(18^{\circ} \mathrm{C}\right)$ allowing $\mathrm{miR}$ 276a function to be turned back on in MB. Both groups were incubated for an additional $72 \mathrm{~h}$ before being tested for LTM. We found that activation of miR-276a function in MB after development was sufficient to support fully normal LTM performance (Fig. $\left.6 M ; F_{(3,28)}=4.35, p<0.05\right)$. In control groups there were no significant differences between temperature-shifted and temperature-unshifted groups. Thus, as with naive olfactory avoidance responses, postdevelopmental function of miR-276a also is sufficient to support LTM.

Together, our findings support the conclusion that naive and conditioned odor responses each require miR-276a function, but in distinct neural circuits. Moreover, in each case DopR is a functional downstream regulatory target. Our data support a model (Fig. 7) in which the levels of DopR are tuned by $m i R-276 a$ within each of these two neural circuits.

\section{Discussion}

MiRNAs have been proposed to provide robustness to gene regulatory networks (Herranz and Cohen, 2010; Peláez and Carthew, 2012), but they can also act as cell fate or developmental switches (Flynt and Lai, 2008). In the brain, perturbations of miRNA biogenesis have major impacts on development, neurodegeneration (Giraldez et al., 2005; Kim et al., 2007a; Schaefer et al., 2007; Berdnik et al., 2008; Cuellar et al., 2008; Davis et al., 2008), and behavior, such as circadian rhythms and memory. For example, disruption in mice of the miRNA-processing enzyme Dicer enhances synaptic plasticity and fear memory (Konopka et al., 2010). Cell type-specific disruption of dicer-1 in Drosophila also impairs circadian behavior (Kadener et al., 2009). Because such disruptions of the miRNA biogenesis and effector machinery affect production or function of all or most miRNAs, it is not unexpected that phenotypic effects are pervasive and pleiotropic. 


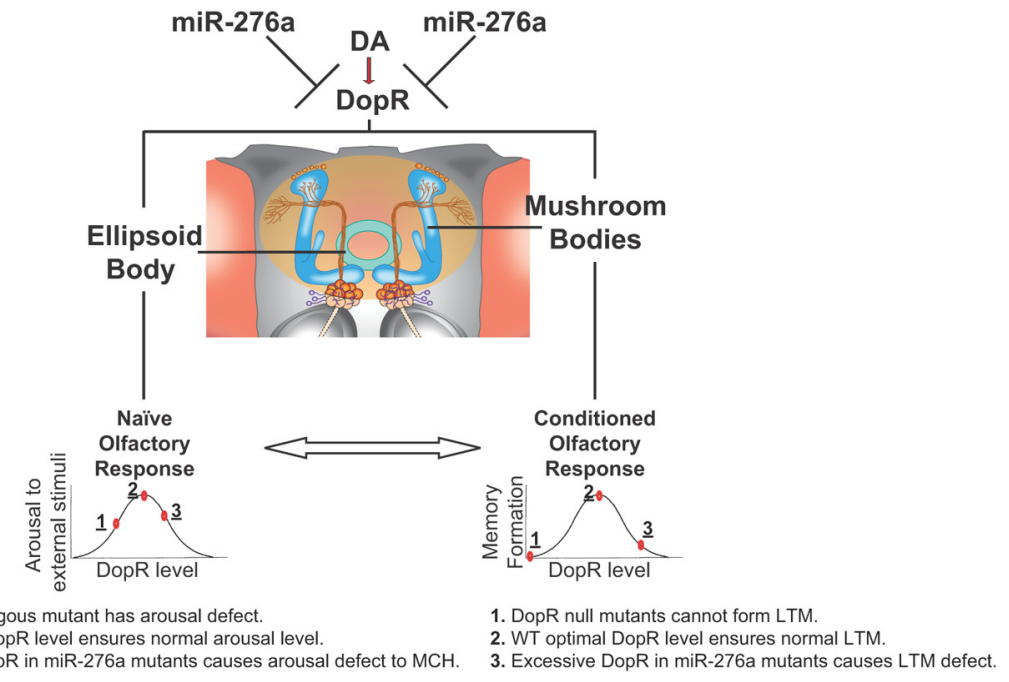

Figure 7. A model in which miR-276a tunes DopR levels in EB and MB for naive olfactory arousal response and LTM. Distinct dopaminergic fibers innervate $E B$ and $M B$ respectively. In EB, DA modulates arousal thresholds via activation of DopR. In $M B \gamma$ neurons, DA release conveys the unconditioned stimulus reinforcement, which is mediated by DopR. Too much or too little DopR expression (red dots) within EB or MB is sufficient to disrupt the normal responses to external stimuli and the formation of LTM. DopR levels normally are tuned by miR-276a to provide an optimal balance. An intriguing hypothesis is that long-lasting plasticity in DopR levels within EB may affect retrieval of LTM by altering arousal to the CS + odor, such as MCH.

MiRNA profiling studies in brain in fact demonstrate that different neuronal cell types express distinct populations of miRNAs and some of the neuronal miRNAs distribute to different subcellular localizations (Lagos-Quintana et al., 2002; Krichevsky et al., 2003; Kim et al., 2004, 2007a; Miska et al., 2004; Sempere et al., 2004; Kaern et al., 2005; Kye et al., 2007; Landgraf et al., 2007; Edbauer et al., 2010; Natera-Naranjo et al., 2010; MiñonesMoyano et al., 2011; He et al., 2012). Moreover, each miRNA gene in principle can regulate many different targets across multiple cell types, and each mRNA can in principle be targeted by multiple miRNAs. Thus cell-type-specific manipulations of individual miRNAs within an in vivo context are needed to decipher underlying mechanisms and functionally relevant targets. A series of recent studies have implicated individual miRNA genes in brain development, neurodegeneration, plasticity, and behavior (Cheng et al., 2007; Karres et al., 2007; Cayirlioglu et al., 2008; Chandrasekar and Dreyer, 2009; Kadener et al., 2009; Rajasethupathy et al., 2009; Gao et al., 2010; Hansen et al., 2010; Magill et al., 2010; Nudelman et al., 2010; Kye et al., 2011; Lin et al., 2011; Mellios et al., 2011; Liu et al., 2012; Luo and Sehgal, 2012). Several of these studies hint at the idea that, for a given phenotype, several miRNAs can converge on a common target, and there are a few cases where phenotypic effects may be mediated largely via one common target (Cayirlioglu et al., 2008; Yoon et al., 2011; Luo and Sehgal, 2012). In the case of memory and synaptic plasticity, there is some evidence for convergence of miRNAs (and Piwi-interacting RNAs) onto CREB as a target (Rajasethupathy et al., 2009, 2012; Gao et al., 2010; Yang et al., 2012). But there still are relatively few cases where miRNA gene function has been established within neural circuits for specific behaviors, and the architecture of downstream regulatory effects of miRNAs on brain function in general and on memory in particular are poorly understood.

We took advantage of both classic and modern Drosophila genetic approaches to manipulate $m i R-276 a$ function in defined neural circuits with temporal specificity. Starting with a hypomorphic allele identified in a forward mutagenesis screen (Dubnau et al., 2003), we engineered a null mutation, precise ex- cisions, BAC rescue transgenes, GAL4responsive transgenes, and a GAL4responsive dominant negative "sponge" transgene. The "sponge" method (Loya et al., 2009; Ebert and Sharp, 2010) in particular provided a means to manipulate $m i R$ $276 a$ function in vivo with cell type and temporal specificity of the GAL4 transactivator system. Proof of principle experiments with "sponges" for miR-7, miR-8, and miR-9a in appropriate tissues produce comparable developmental phenotypes as classic loss-of-function mutant alleles (Loya et al., 2009).

Similarly, the miR-276a "sponge" used in this study was able to phenocopy the effects observed in $m i R-276 a$ mutant animals. Combining this dominant negative "sponge" with GAL4/GAL80 ${ }^{\text {ts }}$ reagents provided the means to dissect miR-276a postdevelopment function underlying two different behavioral phenotypes into distinct neural circuits. This provides the first example in which a miRNA gene's function is demonstrated in behaving animals with both cell-type and temporal specificity. By separately testing effects of miR-276a manipulation within two different neural cell types, we uncovered distinct effects on two related olfactory behaviors. When the sponge was used to interfere with miR-276a function within all neurons, we observed defective responses to odors with naive animals. This precluded a meaningful test of performance in the olfactory memory task. Surprisingly, sponge expression within each of the major cell types of the main olfactory system had no impact on olfactory responses, but when we used the sponge to block miR-276a function in EB neurons, we reproduced the defect in naive responses to $\mathrm{MCH}$. In contrast, sponge expression in $\mathrm{MB}$ neurons did not affect naive responses, which provided an opportunity to test olfactory memory without the confounds that come from odor response defects. The celltype specificity of miR-276a function in c547-labelled R2/R4m $\mathrm{EB}$ neurons for naive responses to $\mathrm{MCH}$ and in $\mathrm{MB}$ intrinsic neurons for LTM also pointed to a functionally relevant downstream target from among those suggested by bioinformatics predictions and QPCR validations.

We focused on DopR both because it contains a conserved miR-276a binding site and because, like miR-276a, DopR function has been mapped to $\mathrm{MB}$ for memory and to $\mathrm{EB}$ for naive responses (odors for miR-276a; ethanol and startle response for DopR). We were able to verify that DopR expression is regulated by miR-276a both at the transcript levels in response to transgenic miR-276a induction and at the protein level within MB in response to "sponge" expression. Although we cannot be certain that the regulation of DopR is direct, the sign of the effect is as predicted for a direct target. More importantly, the regulatory relationship is biologically relevant. Both behaviors are fully suppressed when one copy of DopR gene is removed. This supports the conclusion that overexpression of DopR contributes to both behavioral defects observed in miR-276a mutants. In fact, transgenic DopR overexpression in $\mathrm{MB}$ was sufficient to produce an LTM defect.

Together with evidence from the literature, these findings suggest a model in which DopR expression levels are dosagesensitive both for LTM and for naive behavioral responses. We 
propose that under physiological conditions, a miRNA::DopR regulatory module tunes the levels of DopR in neural circuits underlying naive olfactory responses and olfactory LTM (Fig. 5). In the case of LTM, loss-of-function mutations (Qin et al., 2012) or MB-driven overexpression of DopR (Fig. 4E) each yield decreased memory performance similar to that observed with $\mathrm{MB}$ expression of the miR-276a "sponge." Similarly the effects of EB-driven miR-276a "sponge" are rescued by reducing the copy number of DopR. This dosage sensitivity is consistent with the fact that loss of even one copy of DopR in a miR-276a ${ }^{+/+}$animal causes elevated startle-mediated arousal (Lebestky et al., 2009).

Dopaminergic signaling also has been demonstrated to set thresholds for multiple types of arousal (Van Swinderen and Andretic, 2011). While the role of DopR in these various forms of arousal is complex, effects on ethanol-induced and repetitive startle-induced arousal also have been mapped to c547-labeled $\mathrm{R} 2 / \mathrm{R} 4 \mathrm{~m}$ EB neurons. We thus interpret the reduced naive odor responses with $c 547$-driven miR-276a "sponge" to be a result of reduced olfactory arousal, although this remains to be tested. Also, it should be noted that we have tested the effects of c547EB-driven sponge on naive responses to just one odor, $\mathrm{MCH}$.

The potential connection between EB-mediated arousal and MB-mediated olfactory memory is an intriguing one. NMDA receptor function is in fact required in these same EB neurons for normal LTM formation (Wu et al., 2007). So the EB cell types in which miR276a functions for naive avoidance to $\mathrm{MCH}$ also are a part of the circuit for LTM. One attractive possibility is that behavioral experience modulates functional levels of DopR within $\mathrm{MB}$ and EB. In this case, the observed role of EB on olfactory LTM could derive from long-lasting changes in CS + arousal mediated by a miR-276a::DopR regulatory mechanism.

\section{References}

Andretic R, Kim YC, Jones FS, Han KA, Greenspan RJ (2008) Drosophila D1 dopamine receptor mediates caffeine-induced arousal. Proc Natl Acad Sci U S A 105:20392-20397. CrossRef Medline

Aso Y, Siwanowicz I, Bräcker L, Ito K, Kitamoto T, Tanimoto H (2010) Specific dopaminergic neurons for the formation of labile aversive memory. Curr Biol 20:1445-1451. CrossRef Medline

Bartel DP (2009) MicroRNAs: target recognition and regulatory functions. Cell 136:215-233. CrossRef Medline

Berdnik D, Fan AP, Potter CJ, Luo L (2008) MicroRNA processing pathway regulates olfactory neuron morphogenesis. Curr Biol 18:1754-1759. CrossRef Medline

Betel D, Koppal A, Agius P, Sander C, Leslie C (2010) Comprehensive modeling of microRNA targets predicts functional non-conserved and noncanonical sites. Genome Biol 11:R90. CrossRef Medline

Blum AL, Li W, Cressy M, Dubnau J (2009) Short- and long-term memory in Drosophila require cAMP signaling in distinct neuron types. Curr Biol 19:1341-1350. CrossRef Medline

Busto GU, Cervantes-Sandoval I, Davis RL (2010) Olfactory learning in Drosophila. Physiology (Bethesda) 25:338-346. CrossRef Medline

Cayirlioglu P, Kadow IG, Zhan X, Okamura K, Suh GS, Gunning D, Lai EC, Zipursky SL (2008) Hybrid neurons in a microRNA mutant are putative evolutionary intermediates in insect CO2 sensory systems. Science 319: 1256-1260. CrossRef Medline

Chandrasekar V, Dreyer JL (2009) microRNAs miR-124, let-7d and miR181a regulate cocaine-induced plasticity. Mol Cell Neurosci 42:350-362. CrossRef Medline

Chen CC, Wu JK, Lin HW, Pai TP, Fu TF, Wu CL, Tully T, Chiang AS (2012) Visualizing long-term memory formation in two neurons of the Drosophila brain. Science 335:678-685. CrossRef Medline

Cheng HY, Papp JW, Varlamova O, Dziema H, Russell B, Curfman JP, Nakazawa T, Shimizu K, Okamura H, Impey S, Obrietan K (2007) microRNA modulation of circadian-clock period and entrainment. Neuron 54:813-829. CrossRef Medline

Chiang AS, Lin CY, Chuang CC, Chang HM, Hsieh CH, Yeh CW, Shih CT, Wu JJ, Wang GT, Chen YC, Wu CC, Chen GY, Ching YT, Lee PC, Lin CY,
Lin HH, Wu CC, Hsu HW, Huang YA, Chen JY, et al. (2011) Threedimensional reconstruction of brain-wide wiring networks in Drosophila at single-cell resolution. Curr Biol 21:1-11. CrossRef Medline

Claridge-Chang A, Roorda RD, Vrontou E, Sjulson L, Li H, Hirsh J, Miesenböck G (2009) Writing memories with light-addressable reinforcement circuitry. Cell 139:405-415. CrossRef Medline

Cuellar TL, Davis TH, Nelson PT, Loeb GB, Harfe BD, Ullian E, McManus MT (2008) Dicer loss in striatal neurons produces behavioral and neuroanatomical phenotypes in the absence of neurodegeneration. Proc Natl Acad Sci U S A 105:5614-5619. CrossRef Medline

Czech B, Malone CD, Zhou R, Stark A, Schlingeheyde C, Dus M, Perrimon N, Kellis M, Wohlschlegel JA, Sachidanandam R, Hannon GJ, Brennecke J (2008) An endogenous small interfering RNA pathway in Drosophila. Nature 453:798-802. CrossRef Medline

Davis TH, Cuellar TL, Koch SM, Barker AJ, Harfe BD, McManus MT, Ullian EM (2008) Conditional loss of Dicer disrupts cellular and tissue morphogenesis in the cortex and hippocampus. J Neurosci 28:4322-4330. CrossRef Medline

Dubnau J, Chiang AS, Grady L, Barditch J, Gossweiler S, McNeil J, Smith P, Buldoc F, Scott R, Certa U, Broger C, Tully T (2003) The staufen/pumilio pathway is involved in Drosophila long-term memory. Curr Biol 13:286-296. CrossRef Medline

Ebert MS, Sharp PA (2010) MicroRNA sponges: progress and possibilities. Rna 16:2043-2050. CrossRef Medline

Ebert MS, Neilson JR, Sharp PA (2007) MicroRNA sponges: competitive inhibitors of small RNAs in mammalian cells. Nat Methods 4:721-726. CrossRef Medline

Edbauer D, Neilson JR, Foster KA, Wang CF, Seeburg DP, Batterton MN, Tada T, Dolan BM, Sharp PA, Sheng M (2010) Regulation of synaptic structure and function by FMRP-associated microRNAs miR-125b and miR-132. Neuron 65:373-384. CrossRef Medline

Enright AJ, John B, Gaul U, Tuschl T, Sander C, Marks DS (2003) MicroRNA targets in Drosophila. Genome Biol 5:R1. CrossRef Medline

Flynt AS, Lai EC (2008) Biological principles of microRNA-mediated regulation: shared themes amid diversity. Nat Rev Genet 9:831-842. CrossRef Medline

Gaidatzis D, van Nimwegen E, Hausser J, Zavolan M (2007) Inference of miRNA targets using evolutionary conservation and pathway analysis. BMC Bioinformatics 8:69. CrossRef Medline

Gao J, Wang WY, Mao YW, Gräff J, Guan JS, Pan L, Mak G, Kim D, Su SC, Tsai LH (2010) A novel pathway regulates memory and plasticity via SIRT1 and miR-134. Nature 466:1105-1109. CrossRef Medline

Giraldez AJ, Cinalli RM, Glasner ME, Enright AJ, Thomson JM, Baskerville S, Hammond SM, Bartel DP, Schier AF (2005) MicroRNAs regulate brain morphogenesis in zebrafish. Science 308:833-838. CrossRef Medline

Grün D, Wang YL, Langenberger D, Gunsalus KC, Rajewsky N (2005) microRNA target predictions across seven Drosophila species and comparison to mammalian targets. PLoS Comput Biol 1:e13. CrossRef Medline

Hansen KF, Sakamoto K, Wayman GA, Impey S, Obrietan K (2010) Transgenic miR132 alters neuronal spine density and impairs novel object recognition memory. PLoS One 5:e15497. CrossRef Medline

He M, Liu Y, Wang X, Zhang MQ, Hannon GJ, Huang ZJ (2012) Cell-typebased analysis of microRNA profiles in the mouse brain. Neuron 73:35-48. CrossRef Medline

Herranz H, Cohen SM (2010) MicroRNAs and gene regulatory networks: managing the impact of noise in biological systems. Genes Dev 24:1339-1344. CrossRef Medline

Kadener S, Menet JS, Sugino K, Horwich MD, Weissbein U, Nawathean P, Vagin VV, Zamore PD, Nelson SB, Rosbash M (2009) A role for microRNAs in the Drosophila circadian clock. Genes Dev 23:2179-2191. CrossRef Medline

Kaern M, Elston TC, Blake WJ, Collins JJ (2005) Stochasticity in gene expression: from theories to phenotypes. Nat Rev Genet 6:451-464. CrossRef Medline

Karres JS, Hilgers V, Carrera I, Treisman J, Cohen SM (2007) The conserved microRNA miR-8 tunes atrophin levels to prevent neurodegeneration in Drosophila. Cell 131:136-145. CrossRef Medline

Keene AC, Waddell S (2007) Drosophila olfactory memory: single genes to complex neural circuits. Nat Rev Neurosci 8:341-354. CrossRef Medline

Kim J, Krichevsky A, Grad Y, Hayes GD, Kosik KS, Church GM, Ruvkun G (2004) Identification of many microRNAs that copurify with polyribo- 
somes in mammalian neurons. Proc Natl Acad Sci U S A 101:360-365. CrossRef Medline

Kim YC, Lee HG, Han KA (2007a) D1 dopamine receptor dDA1 is required in the mushroom body neurons for aversive and appetitive learning in Drosophila. J Neurosci 27:7640-7647. CrossRef Medline

Kim J, Inoue K, Ishii J, Vanti WB, Voronov SV, Murchison E, Hannon G, Abeliovich A (2007b) A microRNA feedback circuit in midbrain dopamine neurons. Science 317:1220-1224. CrossRef Medline

Kong EC, Woo K, Li H, Lebestky T, Mayer N, Sniffen MR, Heberlein U, Bainton RJ, Hirsh J, Wolf FW (2010) A pair of dopamine neurons target the D1-like dopamine receptor DopR in the central complex to promote ethanol-stimulated locomotion in Drosophila. PLoS One 5:e9954. CrossRef Medline

Konopka W, Kiryk A, Novak M, Herwerth M, Parkitna JR, Wawrzyniak M, Kowarsch A, Michaluk P, Dzwonek J, Arnsperger T, Wilczynski G, Merkenschlager M, Theis FJ, Köhr G, Kaczmarek L, Schütz G (2010) MicroRNA loss enhances learning and memory in mice. J Neurosci 30: 14835-14842. CrossRef Medline

Krashes MJ, DasGupta S, Vreede A, White B, Armstrong JD, Waddell S (2009) A neural circuit mechanism integrating motivational state with memory expression in Drosophila. Cell 139:416-427. CrossRef Medline

Krichevsky AM, King KS, Donahue CP, Khrapko K, Kosik KS (2003) A microRNA array reveals extensive regulation of microRNAs during brain development. Rna 9:1274-1281. CrossRef Medline

Kye MJ, Liu T, Levy SF, Xu NL, Groves BB, Bonneau R, Lao K, Kosik KS (2007) Somatodendritic microRNAs identified by laser capture and multiplex RT-PCR. Rna 13:1224-1234. CrossRef Medline

Kye MJ, Neveu P, Lee YS, Zhou M, Steen JA, Sahin M, Kosik KS, Silva AJ (2011) NMDA mediated contextual conditioning changes miRNA expression. PLoS One 6:e24682. CrossRef Medline

Lagos-Quintana M, Rauhut R, Yalcin A, Meyer J, Lendeckel W, Tuschl T (2002) Identification of tissue-specific microRNAs from mouse. Curr Biol 12:735-739. CrossRef Medline

Landgraf P, Rusu M, Sheridan R, Sewer A, Iovino N, Aravin A, Pfeffer S, Rice A, Kamphorst AO, Landthaler M, Lin C, Socci ND, Hermida L, Fulci V, Chiaretti S, Foà R, Schliwka J, Fuchs U, Novosel A, Müller RU, et al. (2007) A mammalian microRNA expression atlas based on small RNA library sequencing. Cell 129:1401-1414. CrossRef Medline

Lebestky T, Chang JS, Dankert H, Zelnik L, Kim YC, Han KA, Wolf FW, Perona P, Anderson DJ (2009) Two different forms of arousal in Drosophila are oppositely regulated by the dopamine D1 receptor ortholog DopR via distinct neural circuits. Neuron 64:522-536. CrossRef Medline

Lin Q, Wei W, Coelho CM, Li X, Baker-Andresen D, Dudley K, Ratnu VS, Boskovic Z, Kobor MS, Sun YE, Bredy TW (2011) The brain-specific microRNA miR-128b regulates the formation of fear-extinction memory. Nat Neurosci 14:1115-1117. CrossRef Medline

Liu N, Landreh M, Cao K, Abe M, Hendriks GJ, Kennerdell JR, Zhu Y, Wang LS, Bonini NM (2012) The microRNA miR-34 modulates ageing and neurodegeneration in Drosophila. Nature 482:519-523. CrossRef Medline

Loya CM, Lu CS, Van Vactor D, Fulga TA (2009) Transgenic microRNA inhibition with spatiotemporal specificity in intact organisms. Nat Methods 6:897-903. CrossRef Medline

Lundell MJ, Hirsh J (1992) The zfh-2 gene product is a potential regulator of neuron-specific dopa decarboxylase gene expression in Drosophila. Dev Biol 154:84-94. CrossRef Medline

Luo W, Sehgal A (2012) Regulation of circadian behavioral output via a MicroRNA-JAK/STAT circuit. Cell 148:765-779. CrossRef Medline

Magill ST, Cambronne XA, Luikart BW, Lioy DT, Leighton BH, Westbrook GL, Mandel G, Goodman RH (2010) MicroRNA-132 regulates dendritic growth and arborization of newborn neurons in the adult hippocampus. Proc Natl Acad Sci U S A 107:20382-20387. CrossRef Medline

Margulies C, Tully T, Dubnau J (2005) Deconstructing memory in Drosophila. Curr Biol 15:R700-R713. CrossRef Medline

McGuire SE, Mao Z, Davis RL (2004) Spatiotemporal gene expression targeting with the TARGET and gene-switch systems in Drosophila. Sci STKE 2004:pl6. Medline

Mellios N, Sugihara H, Castro J, Banerjee A, Le C, Kumar A, Crawford B, Strathmann J, Tropea D, Levine SS, Edbauer D, Sur M (2011) miR-132, an experience-dependent microRNA, is essential for visual cortex plasticity. Nat Neurosci 14:1240-1242. CrossRef Medline

Miñones-Moyano E, Porta S, Escaramís G, Rabionet R, Iraola S, Kagerbauer
B, Espinosa-Parrilla Y, Ferrer I, Estivill X, and Marti E (2011) MicroRNA profiling of Parkinson's disease brains identifies early downregulation of miR-34b/c which modulate mitochondrial function. Hum Mol Genet 20:3067-3078. CrossRef Medline

Miska EA, Alvarez-Saavedra E, Townsend M, Yoshii A, Sestan N, Rakic P, Constantine-Paton M, Horvitz HR (2004) Microarray analysis of microRNA expression in the developing mammalian brain. Genome Biol 5:R68. CrossRef Medline

Nakamura M, Baldwin D, Hannaford S, Palka J, Montell C (2002) Defective proboscis extension response (DPR), a member of the Ig superfamily required for the gustatory response to salt. J Neurosci 22:3463-3472. Medline

Natera-Naranjo O, Aschrafi A, Gioio AE, Kaplan BB (2010) Identification and quantitative analyses of microRNAs located in the distal axons of sympathetic neurons. Rna 16:1516-1529. CrossRef Medline

Nudelman AS, DiRocco DP, Lambert TJ, Garelick MG, Le J, Nathanson NM, Storm DR (2010) Neuronal activity rapidly induces transcription of the CREB-regulated microRNA-132, in vivo. Hippocampus 20:492-498. CrossRef Medline

Peláez N, Carthew RW (2012) Biological robustness and the role of microRNAs: a network perspective. Curr Top Dev Biol 99:237-255. CrossRef Medline

Qin H, Cressy M, Li W, Coravos JS, Izzi SA, Dubnau J (2012) Gamma neurons mediate dopaminergic input during aversive olfactory memory formation in Drosophila. Curr Biol 22:608-614. CrossRef Medline

Rajasethupathy P, Fiumara F, Sheridan R, Betel D, Puthanveettil SV, Russo JJ, Sander C, Tuschl T, Kandel E (2009) Characterization of small RNAs in Aplysia reveals a role for miR-124 in constraining synaptic plasticity through CREB. Neuron 63:803-817. CrossRef Medline

Rajasethupathy P, Antonov I, Sheridan R, Frey S, Sander C, Tuschl T, Kandel ER (2012) A role for neuronal piRNAs in the epigenetic control of memory-related synaptic plasticity. Cell 149:693-707. CrossRef Medline

Rollmann SM, Mackay TF, Anholt RR (2005) Pinocchio, a novel protein expressed in the antenna, contributes to olfactory behavior in Drosophila melanogaster. J Neurobiol 63:146-158. CrossRef Medline

Ruby JG, Stark A, Johnston WK, Kellis M, Bartel DP, Lai EC (2007) Evolution, biogenesis, expression, and target predictions of a substantially expanded set of Drosophila microRNAs. Genome Res 17:1850-1864. CrossRef Medline

Schaefer A, O'Carroll D, Tan CL, Hillman D, Sugimori M, Llinas R, Greengard P (2007) Cerebellar neurodegeneration in the absence of microRNAs. J Exp Med 204:1553-1558. CrossRef Medline

Schmittgen TD (2001) Real-time quantitative PCR. Methods 25:383-385. CrossRef Medline

Schratt G, Greenberg M (2007) MicroRNA function in the nervous system. In: MicroRNAs (Appasani K, ed), pp. 115-128. Cambridge: Cambridge UP.

Schwaerzel M, Monastirioti M, Scholz H, Friggi-Grelin F, Birman S, Heisenberg M (2003) Dopamine and octopamine differentiate between aversive and appetitive olfactory memories in Drosophila. J Neurosci 23: 10495-10502. Medline

Sempere LF, Freemantle S, Pitha-Rowe I, Moss E, Dmitrovsky E, Ambros V (2004) Expression profiling of mammalian microRNAs uncovers a subset of brain-expressed microRNAs with possible roles in murine and human neuronal differentiation. Genome Biol 5:R13. CrossRef Medline

Tully T, Quinn WG (1985) Classical conditioning and retention in normal and mutant Drosophila melanogaster. J Comp Physiol A Neuroethol Sens Neural Behav Physiol 157:263-277. CrossRef

Tully T, Preat T, Boynton SC, Del Vecchio M (1994) Genetic dissection of consolidated memory in Drosophila. Cell 79:35-47. CrossRef Medline

Van Swinderen B, Andretic R (2011) Dopamine in Drosophila: setting arousal thresholds in a miniature brain. Proc Biol Sci 278:906-913. CrossRef Medline

Venken KJ, He Y, Hoskins RA, Bellen HJ (2006) P[acman]: a BAC transgenic platform for targeted insertion of large DNA fragments in D. melanogaster. Science 314:1747-1751. CrossRef Medline

Venken KJ, Carlson JW, Schulze KL, Pan H, He Y, Spokony R, Wan KH, Koriabine M, de Jong PJ, White KP, Bellen HJ, Hoskins RA (2009) Versatile P[acman] BAC libraries for transgenesis studies in Drosophila melanogaster. Nat Methods 6:431-434. CrossRef Medline

Wu CL, Xia S, Fu TF, Wang H, Chen YH, Leong D, Chiang AS, Tully T (2007) Specific requirement of NMDA receptors for long-term memory consol- 
idation in Drosophila ellipsoid body. Nat Neurosci 10:1578-1586. CrossRef Medline

Xia S, Miyashita T, Fu TF, Lin WY, Wu CL, Pyzocha L, Lin IR, Saitoe M, Tully T, Chiang AS (2005) NMDA receptors mediate olfactory learning and memory in Drosophila. Curr Biol 15:603-615. CrossRef Medline

Yang Y, Shu X, Liu D, Shang Y, Wu Y, Pei L, Xu X, Tian Q, Zhang J, Qian K, Wang YX, Petralia RS, Tu W, Zhu LQ, Wang JZ, Lu Y (2012) EPAC null mutation impairs learning and social interactions via aberrant regulation of miR-124 and Zif268 translation. Neuron 73:774-788. CrossRef Medline

Yoon WH, Meinhardt H, Montell DJ (2011) miRNA-mediated feedback inhibition of JAK/STAT morphogen signalling establishes a cell fate threshold. Nat Cell Biol 13:1062-1069. CrossRef Medline 